\title{
Uniform corrosion of FeCrAl alloys in LWR coolant environments
}

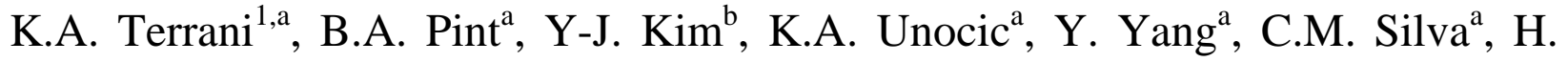 \\ Meyer III ${ }^{\mathrm{a}}$, R.B. Rebak ${ }^{\mathrm{b}}$ \\ ${ }^{a}$ Oak Ridge National Laboratory, Oak Ridge, TN 37831, USA \\ ${ }^{\mathrm{b}}$ GE Global Research Center, Schenectady, NY 12309, USA
}

\begin{abstract}
The corrosion behavior of commercial and model FeCrAl alloys and type 310 stainless steel was examined by autoclave tests and compared to Zircaloy-4, the reference cladding materials in light water reactors. The corrosion studies were carried out in three distinct water chemistry environments found in pressurized and boiling water reactor primary coolant loop conditions for up to one year. The structure and morphology of the oxides formed on the surface of these alloys was consistent with thermodynamic predictions. Spinel-type oxides were found to be present after hydrogen water chemistry exposures, while the oxygenated water tests resulted in the formation of very thin and protective hematite-type oxides. Unlike the alloys exposed to oxygenated water tests, the alloys tested in hydrogen water chemistry conditions experienced mass loss as a function of time. This mass loss was the result of net sum of mass gain due to parabolic oxidation and mass loss due to dissolution that also exhibits parabolic kinetics. The maximum thickness loss after one year of LWR water corrosion in the absence of irradiation was $\sim 2 \mu \mathrm{m}$, which is inconsequential for a $\sim 300-500 \mu \mathrm{m}$ thick cladding.
\end{abstract}

\section{Introduction}

Oxidation resistant $\mathrm{FeCrAl}$ alloys have been proposed as an accident tolerant fuel cladding to replace $\mathrm{Zr}$ based alloys in light water reactors (LWRs) [1]. Under highly oxidizing environments characteristic of LWR severe accidents, the $\mathrm{FeCrAl}$ class of ferritic alloys offer oxidation rates roughly three orders of magnitude slower than Zr-based alloys [2,3]. The slow oxidation kinetics for these alloys can span over a wide temperature range extending all the way to near their melting point $\left(\sim 1500^{\circ} \mathrm{C}\right)$, given that a critical concentration of $\mathrm{Cr}$ and $\mathrm{Al}$ are present in the bulk [4]. This exceptional oxidation resistance is the result of selective oxidation of $\mathrm{Al}$ to form a dense $\alpha-\mathrm{Al}_{2} \mathrm{O}_{3}$ film or scale on the alloy surface. The stable $\alpha$ -

${ }^{1}$ Corresponding author: terranika@ ornl.gov, 865-576-0264

This manuscript has been authored by UT-Battelle, LLC under Contract No. DE-AC05-00OR22725 with the U.S. Department of Energy. The United States Government retains and the publisher, by accepting the article for publication, acknowledges that the United States Government retains a non-exclusive, paid-up, irrevocable, worldwide license to publish or reproduce the published form of this manuscript, or allow others to do so, for United States Government purposes. The Department of Energy will provide public access to these results of federally sponsored research in accordance with the DOE Public Access Plan (http://energy.gov/downloads/doe-publicaccess-plan). 
alumina forms at temperatures above $900^{\circ} \mathrm{C}$ [5] and presents an effective solid-state diffusion barrier to slow the reaction between the oxidizing species and the metal [6]. Alumina is also very stable in steam environments and experiences negligible volatilization for temperatures below $1500^{\circ} \mathrm{C}$ [7].

If FeCrAl alloys are to be used as LWR fuel cladding, their corrosion performance in high temperature, high pressure hydrothermal conditions needs to be assessed. This is the focus of this study where uniform corrosion behavior of these alloys has been examined under hydrothermal conditions characteristic of LWR primary loops. Specifically, immersion tests were carried out inside three autoclaves conforming to pressurized water reactor (PWR), and boiling water reactor (BWR) hydrogen water chemistry (HWC) and normal water chemistry (NWC) conditions. The latter two conditions will examine the difference in behavior under low and high oxygen activity, respectively. Detailed discussions on these water chemistry conditions are available elsewhere [8-10].

Initially, a series of three-month immersion tests were carried out on a set of ferritic and austenitic Febased alloys as well as Zircaloy-4 as reference material. Among the ferritic alloys was a commercial FeCrAl alloy, APMT (Sandvik, Sweden). These short-term exposures indicated satisfactory behavior and longer-term tests were initiated to examine the effects of major alloying elements in FeCrAl alloys. Particularly, the effect of reducing the Cr content, with the aim of reducing neutron-irradiation-induced embrittlement [11-13], was to be investigated. Accordingly, six model $\mathrm{FeCrAl}$ alloy variants were utilized for one-year immersion tests in the three water chemistry conditions of interest.

This paper is organized to first provide an overview of the state of knowledge regarding corrosion behavior of stainless steels in high-temperature water environments. The thermodynamic basis for the formation of protective oxide films on the surface of these alloys as well as kinetic theories describing the corrosion process are reviewed. The next two sections are focused on describing the experimental details and the results of the autoclave tests including characterization of the reaction products. Finally, the last section offers an analysis and discussion of the results.

\section{High-temperature water corrosion of stainless steels}

\subsection{Review of hydrothermal steel corrosion}

Corrosion behavior of stainless steels (austenitic, ferritic, duplex, and ferritic/martensitic) in hightemperature water has been extensively studied [14], especially the austenitic variants [15-22]. The literature suggests that under high temperature aqueous environments without excessive dissolved oxygen, a duplex oxide film forms on the surface of stainless steels. As shown in Fig. 1, this duplex structure consists of a uniform Cr-rich spinel layer adjacent to the metal and octahedral magnetite $\left(\mathrm{Fe}_{3} \mathrm{O}_{4}\right)$ crystals on top of that layer. The corrosion proceeds with growth of the outer oxide, facilitated via outward diffusion of Fe towards the aqueous interface, and concomitant growth of the inner oxide via inward diffusion of the oxidizing species, similar to observations in steam at higher temperatures [23]. Since the oxygen diffuses slowly in the spinel-type films, the latter process is suggested to be taking place via transport of water molecule across macroscopic pores in the Cr-rich spinel [14]. The growth of the outer oxide on the other hand is facilitated by the rapid diffusion of cations in spinel oxides, particularly $\mathrm{Fe}$ [24]. Cr is the slowest diffusing constituent of stainless steels in the spinel-type oxides forming in high-temperature water. While Fe always diffuses faster than $\mathrm{Al}$, Ni diffuses faster and slower than $\mathrm{Fe}$ and $\mathrm{Al}$ under low and high oxygen activity, respectively. The large differences that exist in the diffusivity 
of steel constituents [25] results in selective rejection of rapidly diffusing species from the alloy into the magnetite crystals on the surface.

The rate of rejection of $\mathrm{Fe}$ toward the surface is postulated to be proportional to the growth rate of the inner oxide (since it has to diffuse past the inner Cr-rich spinel) [19]. It has also been suggested that the presence of Cr slows down diffusion of other cations $[14,20]$. The growth of the inner oxide is thought to exhibit parabolic or sub-parabolic kinetics [14, 19].

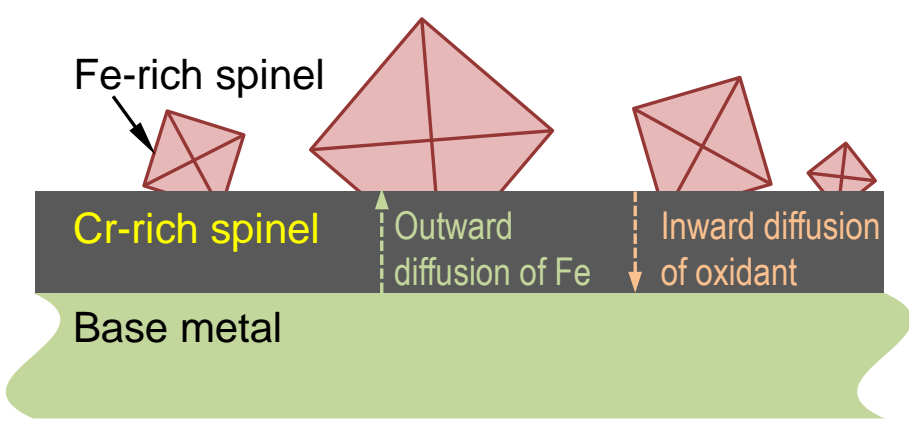

Figure 1. Schematic of the duplex structure of oxide films that form on the surface of stainless steels under hydrothermal conditions in the absence of excessive amounts of dissolved oxygen.

Hydrothermal corrosion behavior of a commercial FeCrAl alloy was evaluated recently [26], although the test environment was not well characterized and the oxygen activity was not controlled. The formation of hematite suggested that an excessive amount of dissolved oxygen was present during the $360{ }^{\circ} \mathrm{C}$ autoclave exposures.

\subsection{Thermodynamic basis}

A basic thermodynamic analysis was carried out to predict the nature of oxide films that are expected to form on $\mathrm{Fe}-10 \mathrm{Cr}$ and $\mathrm{Fe}-18 \mathrm{Cr}$ binary alloys in LWR coolant environments. This analysis omitted the presence of $\mathrm{Al}$ in the $\mathrm{FeCrAl}$ alloys for the sake of simplicity since it becomes apparent in the next sections that Al does not play a major role under these conditions. Thermo-calc $®$ software with the AQueous Solution database (AQS2) [27] was used to determine thermodynamic quantities and to perform equilibrium calculations. This database was specifically developed for calculations of thermodynamic properties of complex aqueous solutions based on the Helgeson-Kirkham-Flowers (HKF) model. This model extends to temperatures up to $1000^{\circ} \mathrm{C}$, pressures up to $5 \mathrm{kbar}$, and aqueous concentrations up to 6 M.

Figure 2 shows the calculated Pourbaix diagram of the two $\mathrm{Fe}-\mathrm{Cr}$ alloys in water at $290^{\circ} \mathrm{C}-7.5 \mathrm{MPa}$ and $330^{\circ} \mathrm{C}-15 \mathrm{MPa}$, corresponding to BWR and PWR temperature-pressure combinations, respectively. Note that the predicted behavior between the two alloys exhibits negligible dependence on the $\mathrm{Cr}$ concentration within the 10-18wt\% range. In the case of BWR-HWC and PWR conditions, the formation of magnetite and chromite $\left(\mathrm{FeCr}_{2} \mathrm{O}_{4}\right)$ was predicted. However, note that in case of PWR conditions, the $\mathrm{pH}$ and potential combinations are close to the region where hematite $\left(\mathrm{Fe}_{2} \mathrm{O}_{3}\right)$ formation is expected. For BWR-NWC conditions the higher oxides, chromia and hematite, are expected to form on the surface of the alloys. It is expected that these oxides will form a solid solution [28, 29]. 


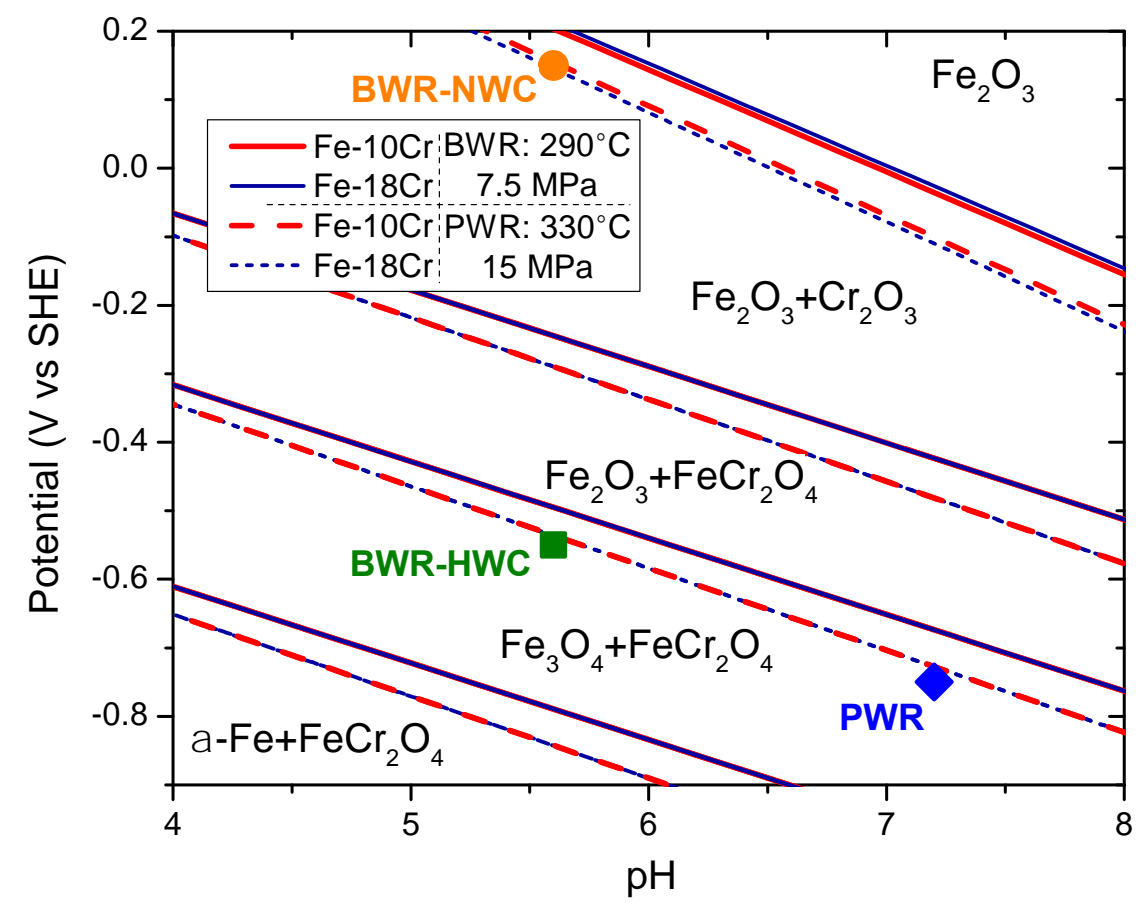

Figure 2. Pourbaix diagram of Fe-10Cr and Fe-18Cr alloys under BWR and PWR conditions. SHE abbreviates standard hydrogen electrode.

\section{Experimental details}

Initially, coupons $(\sim 1 \times 2 \times 0.15 \mathrm{~cm})$ of an austenitic stainless steel $(310 \mathrm{SS})$, a commercial ferritic alloy (E-Brite), and a commercial FeCrAl alloy (APMT) were exposed alongside disks from a Zircaloy-4 rod used as reference material for a period of three months. Following those exposures, six model $\mathrm{FeCrAl}$ alloys prepared at ORNL [30] underwent immersion testing for a period of one year. The six alloys consisted of five distinct compositions with the intention of exploring the effect of major alloying elements (i.e. $\mathrm{Cr}$, and $\mathrm{Al}$ ) on corrosion behavior. As the $\mathrm{Cr}$ content of the alloys was reduced, the $\mathrm{Al}$ concentration was increased. In this manner the critical combination of $\mathrm{Cr}$ - $\mathrm{Al}$ content in these alloys was maintained to preserve adequate high-temperature steam oxidation resistance at $1200^{\circ} \mathrm{C} \mathrm{[4]}$. Coupons from all five of these compositions were prepared with a grain size in the rnage of 250-900 $\mu \mathrm{m}$. To explore the effect of grain size, another coupon of Fe-13Cr-4Al with grain size in the rnage of 20-35 $\mu \mathrm{m}$ was also tested. The detailed production and heat treatment schedueles are described in ref. [30]. The measured composition for all the alloys in this study is described in Table 1. The specimens were polished to a 600 grit finish and cleaned ultrasonically in acetone prior to immersion tests. The immersion tests were conducted in 1 gallon (3.78 liter) 316 stainless steel (SS) autoclaves at GE Global Research Center (Schenectady, NY). The samples were extracted from the autoclaves at various time intervals and weighed three times each with accuracy of $10 \mu \mathrm{g}$. The mass change was reported as the average change in mass from three specimens of each material in each autoclave. In case of the model alloys one specimen was removed for characterization at the end of five months. 
Table 1. Alloy compositions (wt\% or ppmw for O,C, and S) determined by inductively coupled plasma and combustion techniques.

\begin{tabular}{|l|cccccccccccc|}
\hline Alloy ID & Fe & Cr & Al & Y & Zr & Ni & Mo & Si & O & C & S & Other \\
\hline Zircaloy-4 & 0.2 & 0.1 & - & - & 98.2 & & & 0.01 & 1180 & 160 & $<$ & $1.27 \mathrm{Sn}$ \\
310SS & 51.9 & 25.4 & - & - & & 19.5 & 0.13 & 0.70 & 60 & 440 & 11 & $1.89 \mathrm{Mn}, 0.15 \mathrm{Co}, 0.1 \mathrm{Cu}$ \\
E-BRITE & 72.6 & 25.8 & - & - & & 0.13 & 1 & 0.22 & 30 & 30 & 100 & $0.1 \mathrm{Nb}, 0.1 \mathrm{~V}$ \\
APMT & 69.0 & 21.6 & 4.9 & 0.12 & 0.1 & 0.12 & 2.8 & 0.53 & 490 & 300 & $<$ & $0.16 \mathrm{Hf}, 0.1 \mathrm{Mn}$ \\
Fe18Cr3Al & 79.3 & 17.5 & 3.0 & 0.02 & $<$ & $<$ & $<$ & 0.01 & 21 & 33 & 11 & $0.2 \mathrm{~W}$ \\
Fe15Cr4Al & 81.2 & 14.9 & 3.9 & 0.01 & $<$ & $<$ & $<$ & 0.01 & 16 & 28 & 13 & $0.07 \mathrm{~W}$ \\
Fe13Cr4Al-SG* & 83.0 & 13.0 & 3.9 & 0.01 & $<$ & $<$ & $<$ & $<$ & 10 & 60 & 15 & \\
Fe13Cr4Al & 83.0 & 13.0 & 3.9 & 0.01 & $<$ & $<$ & $<$ & $<$ & 10 & 60 & 15 & \\
Fe12Cr5Al & 83.6 & 12.0 & 4.4 & 0.03 & $<$ & $<$ & $<$ & 0.01 & 17 & 50 & 13 & \\
Fe10Cr5Al & 85.2 & 10.0 & 4.8 & 0.04 & $<$ & $<$ & $<$ & $<$ & 13 & 50 & 13 & \\
\hline
\end{tabular}

Notes: *small grain material, < denotes below the detectable limit of $0.01 \%$ or $0.001 \%$ for interstitials.

A demineralizer, an organic removal column, and a submicron filter were used to purify the water in the test loop before passing through the 1 gallon (3.78 liter) glass conditioning column. Inside this column the water, passing at a flow rate of $200 \mathrm{cc} / \mathrm{min}$, was equilibrated with appropriate mixtures of $\mathrm{Ar}, \mathrm{O}_{2}$, and $\mathrm{H}_{2}$ to establish the desired water chemistry. The dissolved oxygen and hydrogen in the inlet and outlet streams were measured via SWAN FAM Oxytrace and Hach Orbisphere Model 26322 monitors, respectively. A platinum flag electrode was used to monitor the effective redox potential of the water. This was done alongside an Agilent 34970A Electrometer using a zirconia high temperature $\mathrm{pH}$ sensor with a copper/cuprous oxide internal junction $\left(\mathrm{ZrO}_{2} / \mathrm{Cu} / \mathrm{Cu}_{2} \mathrm{O}\right)$ as a reference electrode at high temperature. The water conductivity was not reported during the tests. The potential in each autoclave was calculated and reported in a previous study [31]. The details of the environmental conditions during the simulated PWR, BWR-HWC, and BWR-NWC water chemistries are provided in Table 2.

Table 2. Summary of autoclave conditions for immersion tests.

\begin{tabular}{|l|c|c|c|c|c|}
\hline Autoclave & Chemistry & $\begin{array}{c}\text { Temperature } \\
\left({ }^{\circ} \mathbf{C}\right)\end{array}$ & $\mathbf{p H}$ & $\begin{array}{c}\text { Redox Potential } \\
(\mathbf{m V} \text { vs SHE) }\end{array}$ & $\begin{array}{c}\text { Pressure } \\
(\mathbf{M P a})\end{array}$ \\
\hline PWR & $3.57 \mathrm{ppm} \mathrm{H}_{2}$ & 330 & 7.2 & -820 & 15 \\
\hline BWR-HWC & $0.3 \mathrm{ppm} \mathrm{H}_{2}$ & 290 & 5.6 & -540 & 7 \\
\hline BWR-NWC & $1.0 \mathrm{ppm} \mathrm{O}_{2}$ & 290 & 5.6 & 350 & 7 \\
\hline
\end{tabular}


Upon completion of the immersion tests, the specimens were characterized using scanning electron microscopy (SEM) with a JEOL 6500 FEG-type microscope operating at an accelerating potential of 15 $\mathrm{kV}$. X-ray diffraction (XRD) studies were performed with a Rigaku MiniFlex Ii XRD instrument of 0.45 $\mathrm{kW}(30 \mathrm{kV}$ and $15 \mathrm{~mA}$ ) with $\mathrm{Cu}-\mathrm{K} \alpha$ radiation. Rietveld refinement of the XRD patterns was carried out using GSAS [32]. X-ray photoelectron spectroscopy (XPS) was carried out on a Thermo Scientific KAlpha XPS instrument with X-ray spot diameter of $400 \mu \mathrm{m}$. XPS depth profiles were acquired with a $2 \mathrm{kV}$ Ar-ion beam. Ion gun parameters were calibrated in separate experiments and were determined to yield etch rates on standard $\mathrm{SiO}_{2}$ films of $13 \mathrm{~nm} / \mathrm{min}$. Scanning transmission electron microscopy (STEM) specimens were prepared using the focused ion beam lift out technique and imaging was carried out using JEOL model 2200FS-AC STEM with a $200 \mathrm{kV}$ probe-corrected beam (using CEOS $\mathrm{C}_{\mathrm{s}^{-}}$ Corrector) that is equipped with a Bruker XFlash ${ }^{\circledR} 6 \mid 30$ silicon drift detector.

\section{Results and analysis}

\subsection{Mass change after autoclave testing}

Figure 3 shows the specimen mass change of the commercial alloy coupons after the initial autoclave immersion tests. For the Fe-based alloys, ferritic or austenitic, the trends are consistent; in hydrogen water chemistries (PWR, and BWR-HWC) they exhibited mass loss, while in the case of high oxygen water chemistry (BWR-NWC) they experienced mass gain. Note that the extent of mass loss and gain for the Fe-based alloys was quite negligible when converted to metal loss or oxide thickness. If one assumes mass loss is associated with metal dissolution and mass gain associated with oxide growth, $10 \mathrm{mg} / \mathrm{dm}^{2}$ corresponds to $\sim 0.1 \mu \mathrm{m}$ of metal loss and $\sim 0.6 \mu \mathrm{m}$ of oxide thickness, respectively. The commercial $\mathrm{FeCrAl}$ alloys, APMT, that has a slightly smaller $\mathrm{Cr}$ content than the ferritic E-Brite and austenitic 310SS, showed a higher mass loss in hydrogen water chemistries. In all cases, the rate of mass loss appeared to slow with exposure time.

Consistent with myriad prior observations, Zircaloy-4 showed mass gains in all cases, the extent of which increased at higher temperatures (PWR vs. BWR-HWC) and higher oxygen activity (BWR-NWC vs. BWR-HWC). No sign of transition (periodic increase in mass gain rate due to defects forming as a result of stress associated with the growing oxide layer [33]) was apparent in any of the Zircaloy-4 mass gain curves during this test period [34].

Figure 4 shows the mass change of the model $\mathrm{FeCrAl}$ alloy specimens after one year of autoclave immersion tests in the various LWR water chemistries. The data points are the average values for three specimens up to five months and two specimens beyond that point. The error bars represent the standard error in the average. The overall trends proved similar to those of the commercial Fe-based alloys where the alloy specimens experience mass loss in PWR and BWR-HWC water chemistries and mass gains under BWR-NWC conditions. Although, there exists a notable variation in the mass change trend between the various alloys, it does not appear to be systematically related to the alloy composition or grain size. Similar to the commercial Fe-based alloys, the thickness variation estimated from the extent of mass change in the model alloys was quite small. Some specimens experienced a mass loss at the end of the BWR-NWC exposures. This mass loss could be a result of oxide spallation but the oxides are 
relatively thin and are unlikely to have sufficient strain energy after cooling (associated with any growth and/or thermal stress) to cause spallation.

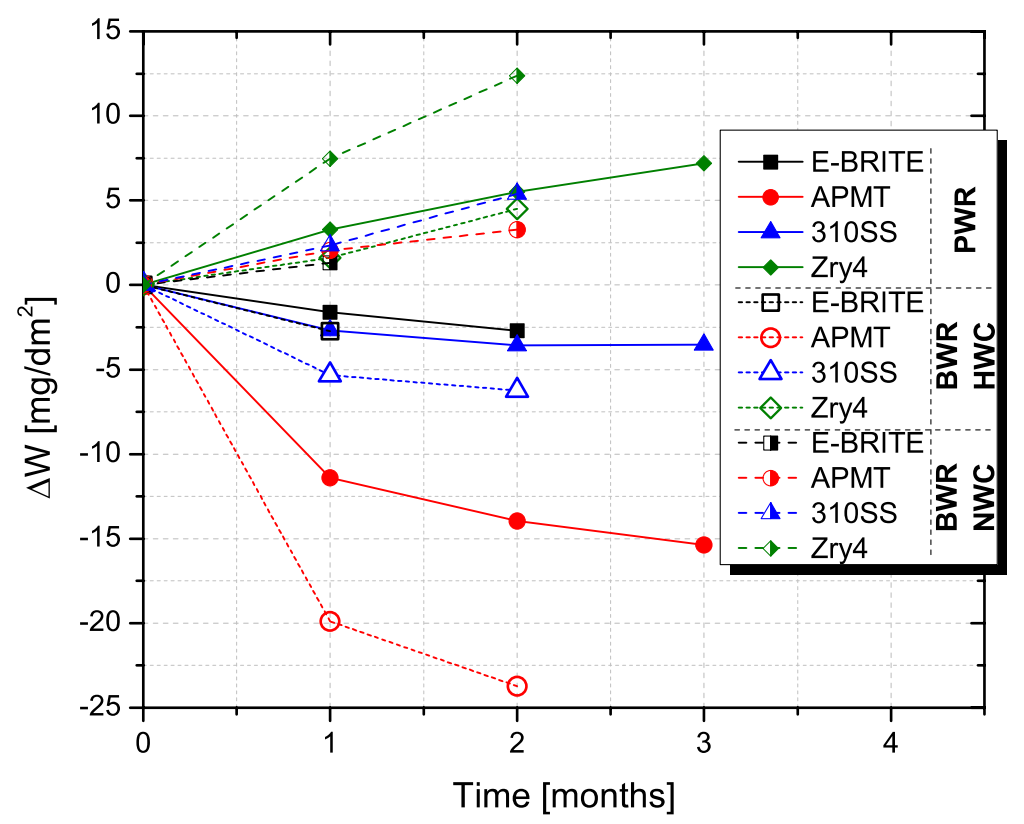

Fig. 3. Mass change in commercial Fe-based alloys and Zircaloy-4 after autoclave immersion tests. 

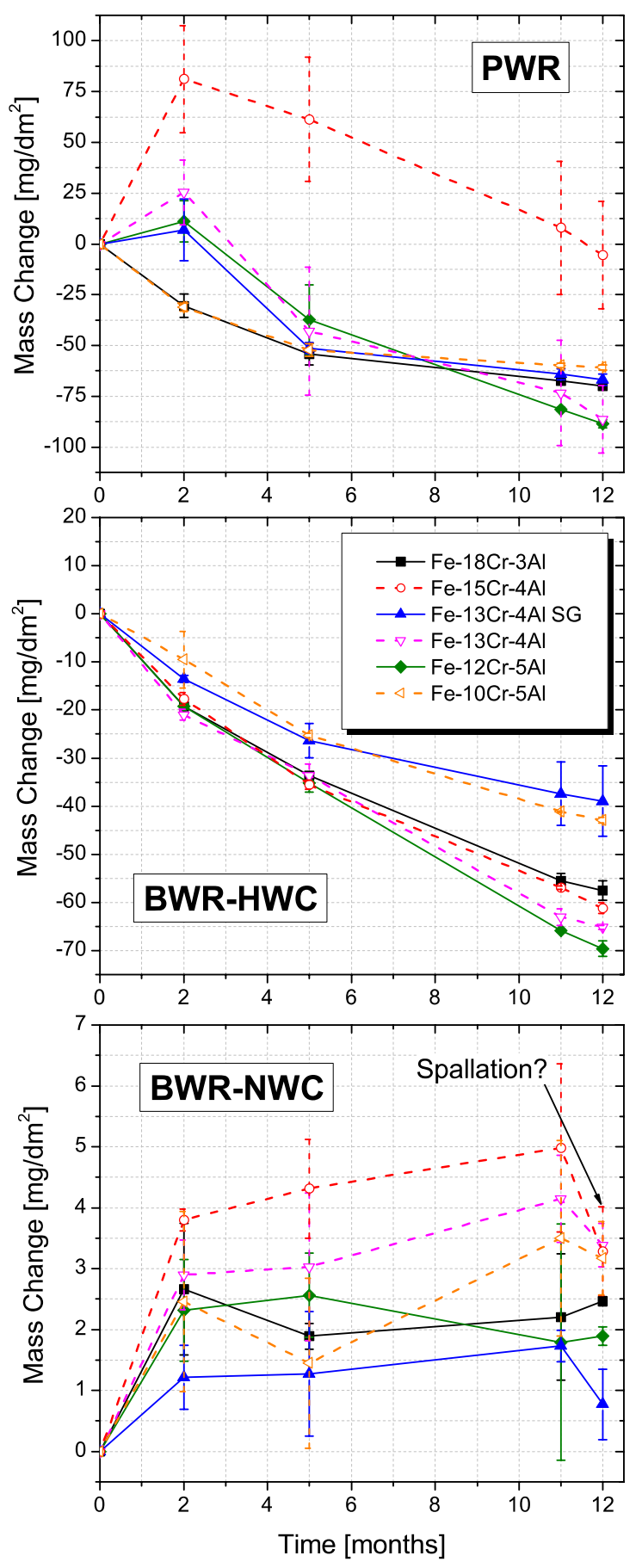

Fig. 4. Mass change in model $\mathrm{FeCrAl}$ alloys as a function of autoclave immersion time.

\subsection{Post-exposure characterization}

4.2.1. X-ray photoelectron spectroscopy 
The APMT and 310SS specimens were examined using XPS, Figure 5. For many of the metal elements, both oxide and metallic components were observed. In those cases, peak fitting was used to separate the two components. The depth profile results for BWR-HWC conditions are omitted since they were similar to the PWR results. For both alloys, a thinner oxide was observed after 3 months of exposure in PWR water chemistry compared to 2 months of BWR-NWC immersion. For APMT, Al was not an important constituent of the oxide layers and in fact appeared to be depleted in the scale. For both the austenitic and ferritic alloys, the oxide was more enriched in $\mathrm{Cr}$ after the PWR exposures. Ziemniak and Hanson performed surface depth profiling of $304 \mathrm{SS}$ corroded in $260^{\circ} \mathrm{C}$, hydrogenated water [21]. After roughly 7 months of exposure, a much thicker oxide was reported that had a different oxygen-to-metal ratio and metal constituent composition than what was observed here for 310SS. These discrepancies may be explained by the composition difference in the base alloy.

BWR-NWC immersion tests produce a more Fe-rich oxide and in case of APMT, a significant amount of Ni was incorporated into this oxide (the source of Ni could be the other specimens being exposed or from the structural materials in the water loop). The oxide layer thickness on the BWR-NWC exposed APMT alloy appeared significantly larger than one would predict from the mass gain in Figure 3. After deconvolution of the signal to determine the oxidized or metallic nature of the metal elements it became obvious that $\mathrm{Fe}, \mathrm{Cr}$, and $\mathrm{Al}$ all exhibited an oxidized nature near the surface and switched to the metallic state as the depth increased. Consistent with their oxide stabilities, the switch from oxide to metal state occurred earlier for $\mathrm{Fe}$, then $\mathrm{Cr}$, and finally $\mathrm{Al}$. The Ni incorporated into the oxide layer of the BWRNWC exposed APMT specimen only exhibited an oxidized nature.

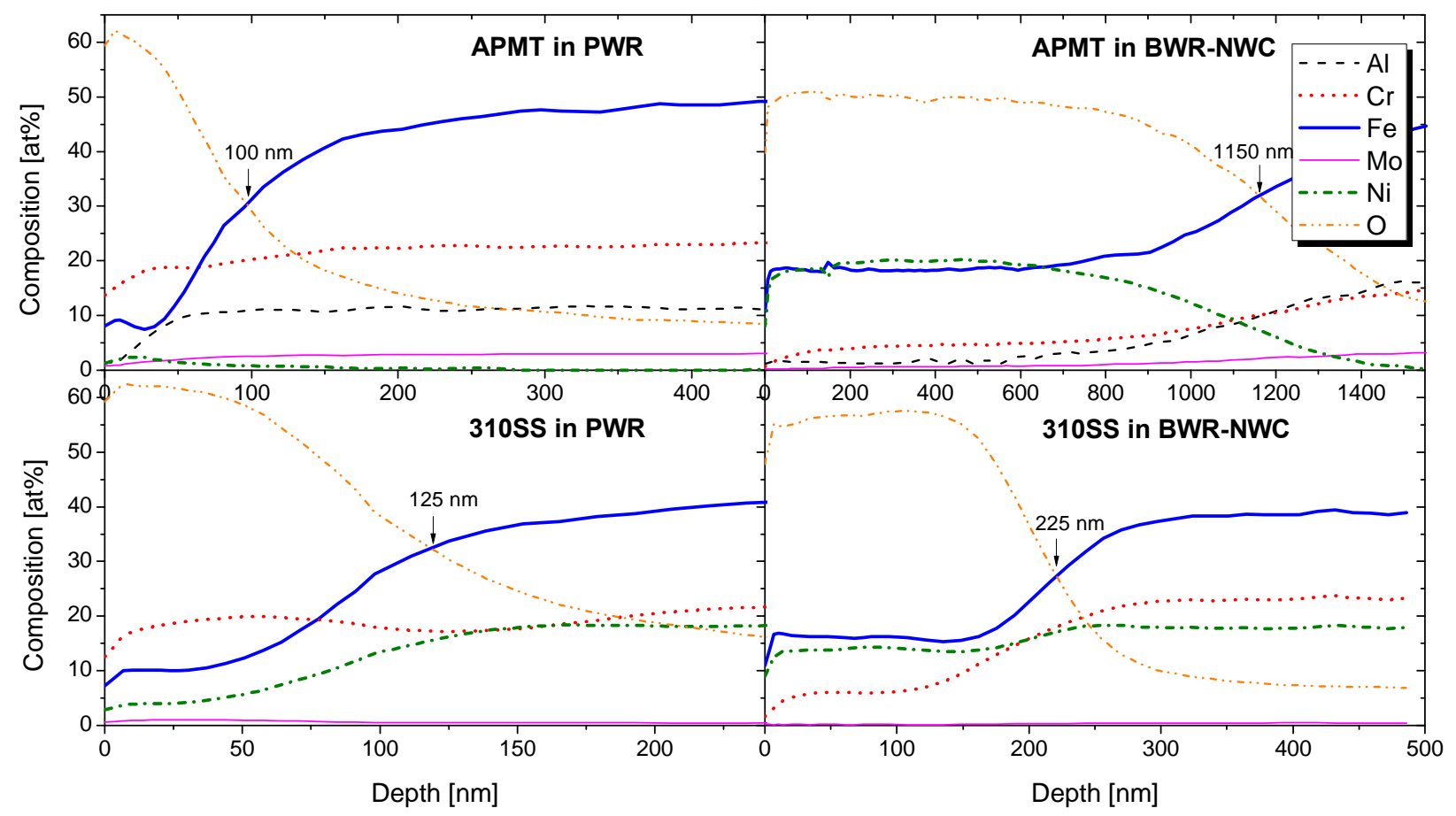

Fig. 5. Composition vs. depth from XPS spectra from APMT and 310SS after the PWR (3 months) and BWR-NWC ( 2 months) immersion tests. Note the largely different depth ranges for the different samples on the horizontal axes. 


\subsubsection{X-ray diffractometry}

Specimens also were examined via XRD to determine the structure of the oxide films. The results for the APMT and 310SS specimens after 2 months of BWR-NWC exposures are shown in Fig. 6. A spinel-type oxide was observed. No discernable oxide patterns were detected on these specimens after PWR and BWR-HWC exposures, indicating the presence of only very thin scales and consistent with the observations in Fig. 5. The presence of a spinel-type oxide after the BWR-NWC exposure was not consistent with what is expected from the Pourbaix diagram in Figure 2.

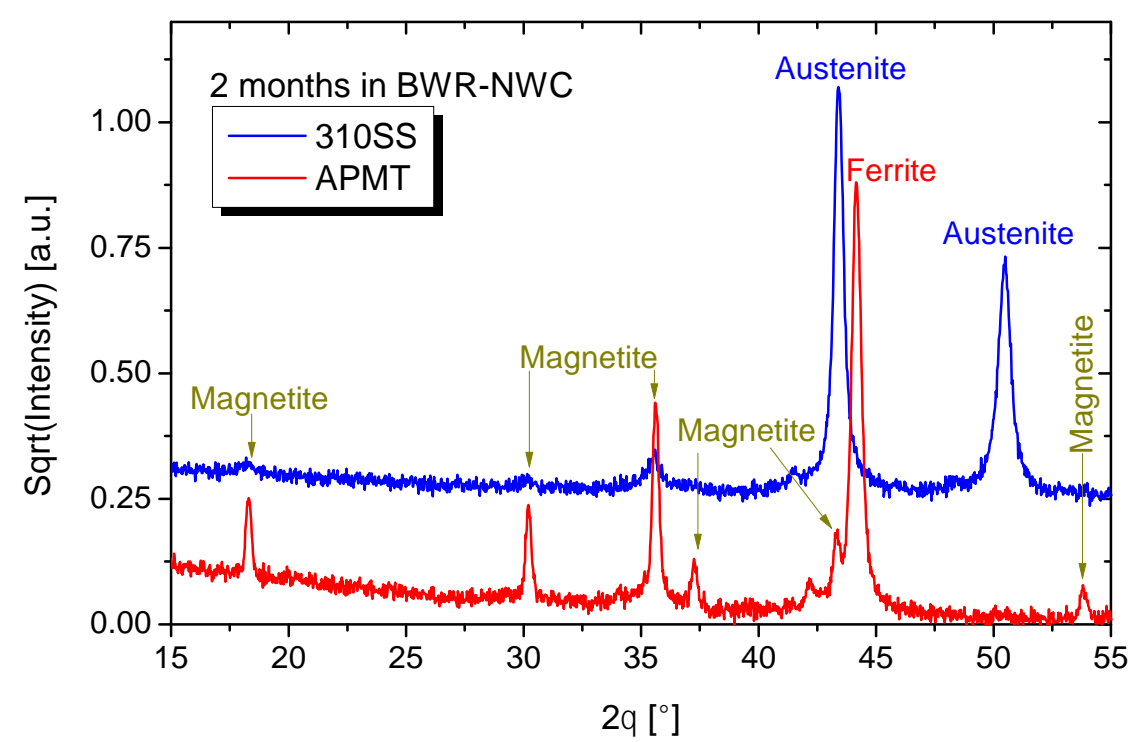

Fig. 6. XRD spectra from APMT and 310SS specimens after 2 months of BWR-NWC immersion tests.

The XRD spectra from select model FeCrAl alloys are shown in Figure 7. After Rietveld refinement was completed on all the patterns, phase fractions (in wt\%) of the various oxide structures, namely wüstite $(\mathrm{FeO})$, magnetite $\left(\mathrm{Fe}_{3} \mathrm{O}_{4}\right)$, and hematite $\left(\mathrm{Fe}_{2} \mathrm{O}_{3}\right)$ were determined, Figure 8. For BWR exposures, the presence of excess hydrogen and oxygen clearly resulted in the strong formation of magnetite and hematite, respectively. The oxygen stoichiometry of the oxide was consistent with the oxygen activity in the water and the results agree well with what is predicted in the Pourbaix diagram, Figure 2. For the PWR exposures, the resulting oxides were a mixture of these two phases, though magnetite appeared to be the dominant oxide for the lower Cr containing alloys.

Since a Si standard was used during the XRD tests, a somewhat accurate measurement of the lattice parameter of these various oxides was possible. No effect of alloy composition on the lattice parameter of the $\mathrm{M}_{2} \mathrm{O}_{3}$ oxides formed after BWR-NWC exposures was observed. Since the oxide layer in this series was very thin (see next sections) determination of the exact lattice parameter was challenging. Both hematite and eskolaite $\left(\mathrm{Cr}_{2} \mathrm{O}_{3}\right)$ have the corundum structure and are fully miscible (though not with $\mathrm{Al}_{2} \mathrm{O}_{3}$ [35] in the pertinent temperature range) [36]. The lattice parameter of the solid solution varied nonlinearly with composition and tended to decrease with increasing $\mathrm{Cr}$ content. The lattice parameters $a$ and $c$ in these oxides varied between 0.5016 to $0.5045 \mathrm{~nm}$ and 1.3721 to $1.3775 \mathrm{~nm}$, respectively. This implies that 
the maximum $\mathrm{Cr}_{2} \mathrm{O}_{3}$ content of these oxides was $\leq 40 \%$ [37] and a significant fraction of the protective oxide consisted of $\alpha-\mathrm{Fe}_{2} \mathrm{O}_{3}$.

The thicker oxides present on the surface of PWR and BWR-HWC exposed specimens (shown in the next subsection) produced more reliable lattice parameter data. The variation of the lattice parameters for the spinel oxide as a function of $\mathrm{Cr}$ content in the model alloys is shown in Figure 9. Under both hydrogen water chemistry conditions, an increase in the lattice parameter was observed with increasing $\mathrm{Cr}$ content in the base alloy, though this was much more reliably observed after PWR immersion tests. Comparing these lattice parameters to literature data [38-40], it is apparent that these values are all smaller than the minimum reported in the binary magnetite-chromite spinel mixtures. This could be due to the presence of hercynite $\left(\mathrm{FeAl}_{2} \mathrm{O}_{4}\right)$, which has a smaller lattice parameter [41, 42]. The apparent increase in lattice parameter with increasing $\mathrm{Cr}$ content in the alloy is more difficult to explain. It may be indicative of a $\mathrm{Cr}$ content in the range of $\mathrm{x}=0.8-1.2$ in the $\mathrm{FeFe}_{2-\mathrm{x}} \mathrm{Cr}_{\mathrm{x}} \mathrm{O}_{4}$ oxide where the lattice parameter tends to increase in magnetite-chromite mixtures [39]. On the other hand, it could be due to the reduced Al content in the alloy with increasing $\mathrm{Cr}$ content and correspondingly less $\mathrm{Al}$ in the mixed oxide. If it is due to the increase in the $\mathrm{Cr}$ content in the oxide films, it might also explain the slightly larger lattice parameters observed for the small grain alloy where $\mathrm{Cr}$ diffusion via the grain boundaries to the oxide may be enhanced.

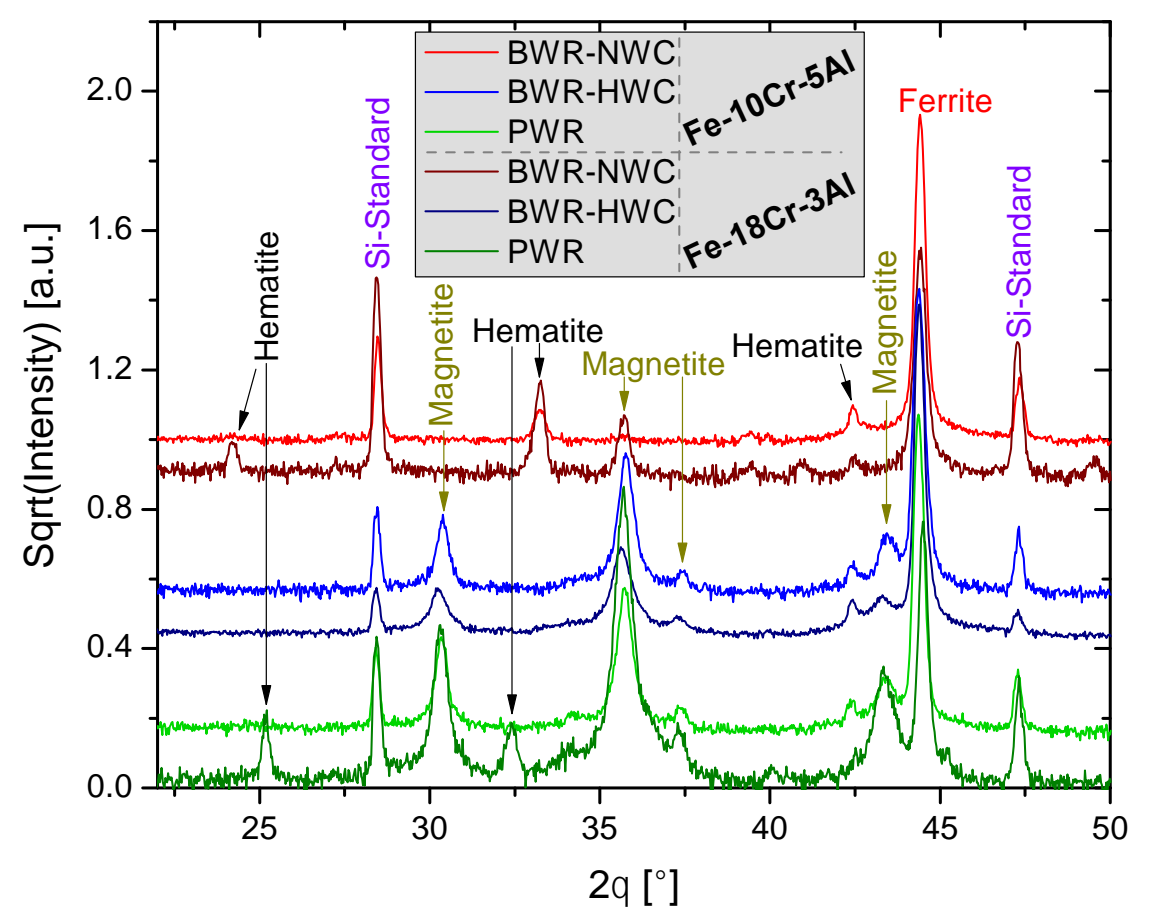

Fig. 7. XRD spectra from Fe-10Cr-5Al and Fe-18Cr-3Al model alloys after one year of PWR and BWR immersion tests. 


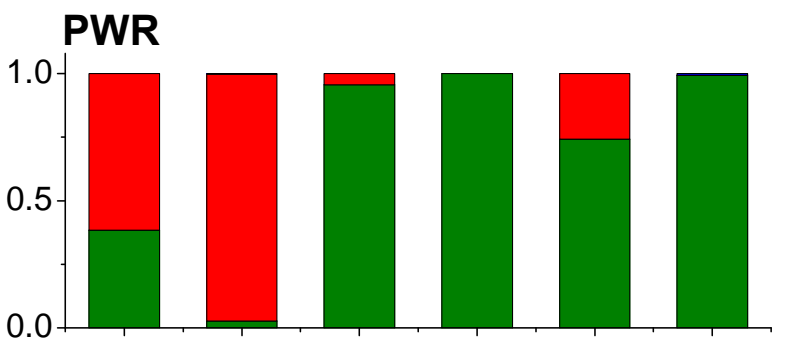

\section{BWR-HWC}

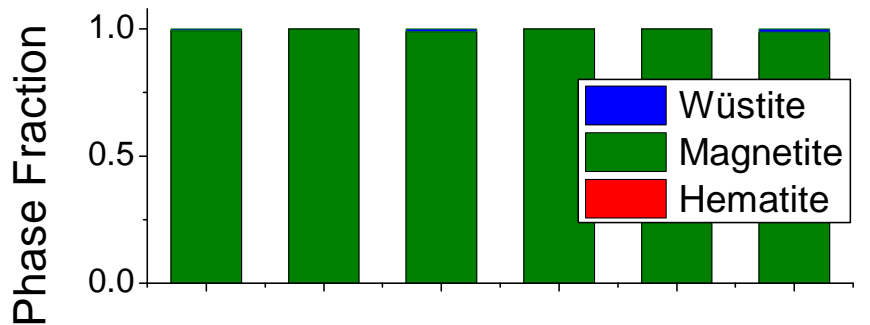

\section{BWR-NWC}

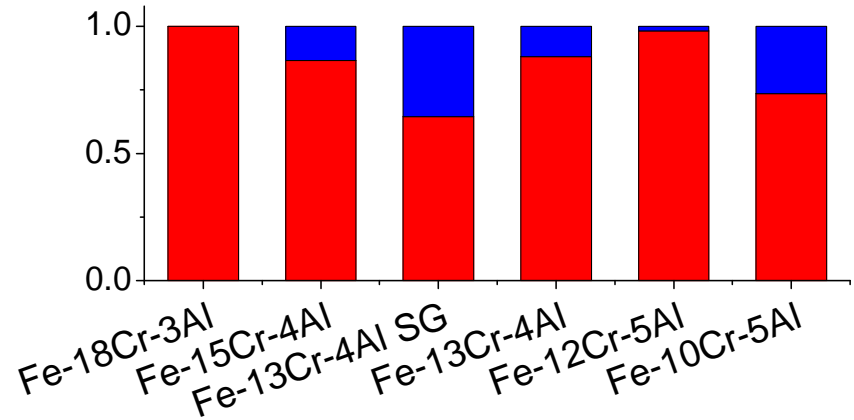

Fig. 8. Phase fraction in wt $\%$ of various oxide phases present on the surface of model FeCrAl alloys after 1 year of PWR and BWR immersion tests. The oxide structures correspond to wüstite $(\mathrm{FeO})$, magnetite $\left(\mathrm{Fe}_{3} \mathrm{O}_{4}\right)$, or hematite $\left(\mathrm{Fe}_{2} \mathrm{O}_{3}\right)$.

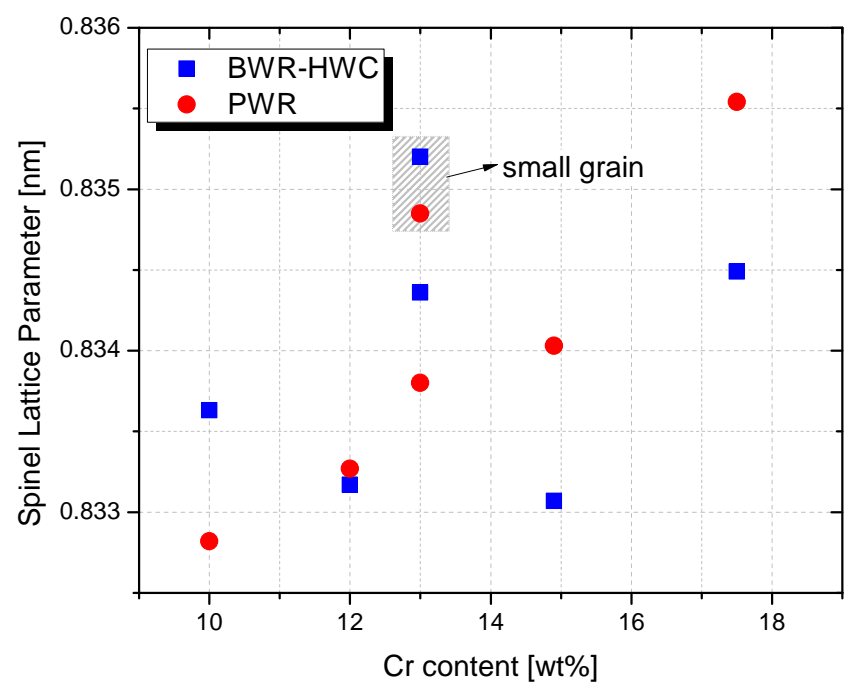

Fig. 9. The variation of the lattice parameters $\mathrm{M}_{3} \mathrm{O}_{4}$ oxide as a function of $\mathrm{Cr}$ content in the model alloys. 


\subsubsection{Light Microscopy and SEM Observations}

Figure 10 shows the surface morphology of the lowest and highest Cr-containing model alloy specimens after the various immersion tests. After BWR-NWC exposures, a dense mosaic network of crystals was observed. Based on the XRD analysis in the prior section, these are likely $\mathrm{M}_{2} \mathrm{O}_{3}$ crystals where $\mathrm{M}$ is a mixture of Fe and Cr. In the case of the PWR and BWR-HWC exposures, the surface consists of sporadic Fe-rich spinel crystals on top of a uniform Cr-rich spinel-type oxide layer. Note that the surface appearance of the Fe-18Cr-3Al alloy appears the same after one year of PWR and BWR-HWC exposures, even though the XRD analysis indicated the presence of $\mathrm{M}_{2} \mathrm{O}_{3}$ in addition to the spinel oxide after the PWR exposure.

Figure 11 shows light microscopy of polished cross-sections of the scales formed on high-, medium-, and low-Cr contents after 1 year of PWR and BWR-HWC immersion tests. The oxides formed under BWRNWC were too thin to be observed by light microscopy and instead were imaged by SEM, Figure 12. All of the specimens were $\mathrm{Cu}$-plated prior to metallographic sectioning to preserve the oxide layer and provide good contrast between the oxide layer and the mount. However, in most cases the Cu layer peeled away from the relatively flat oxide layer. The light microscopy images indicate that the oxide thickness after one year in PWR and BWR-HWC was quite uniform on the various alloys. The SEM images show a thin sub-micrometer oxide layer, irrespective of the alloy composition, after BWR-NWC exposure. The oxide layer was substantially thicker after exposures in the hydrogen water chemistries and appeared to increase in thickness with increasing $\mathrm{Cr}$ content in the alloys. The thicker oxides on the surface of alloys tested in hydrogen water chemistry conditions vs. BWR-NWC may appear unintuitive given the earlier mass loss results shown in Figure 4 for these conditions and mass gain for BWR-NWC conditions. However, this mass loss is the net result of mass gain due to parabolic oxidation and mass loss due to dissolution and is discussed in detail un section 5.1.

The oxide thickness in select alloys after 5 month and 12 month hydrogen water chemistry immersion tests was determined using light microscopy. The available oxide thickness data on these alloys is shown in Fig 13. The oxide layer after BWR-HWC tests tended to be thinner when compared to PWR tests.

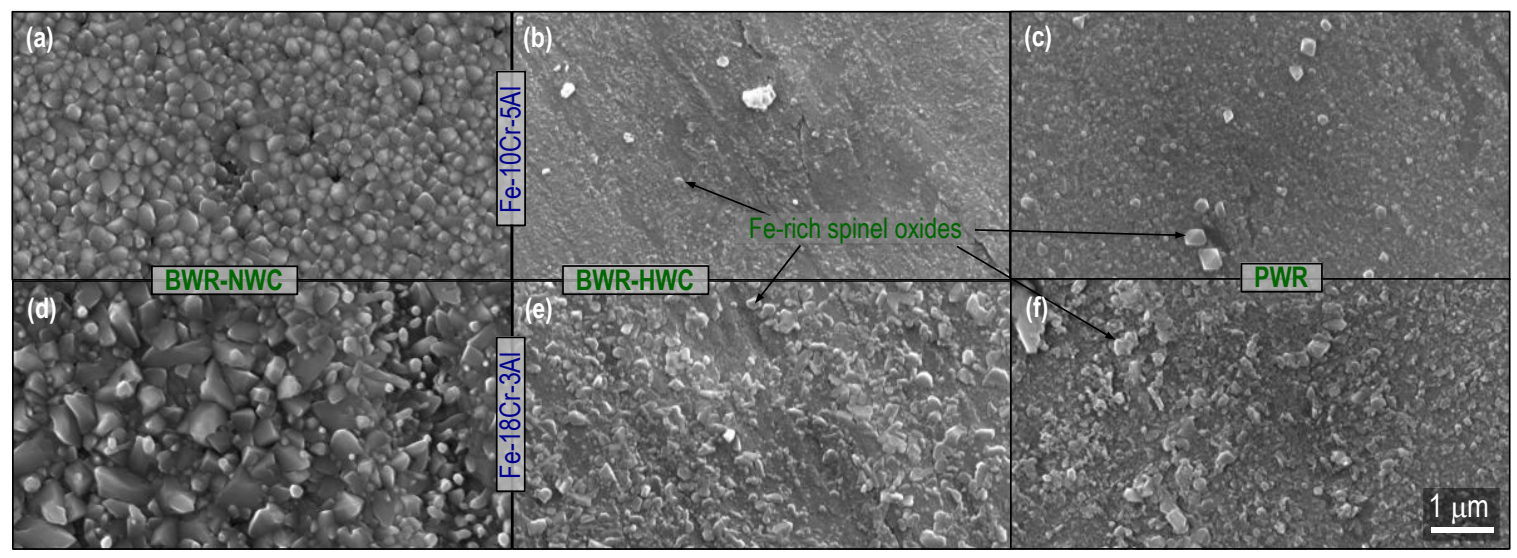

Fig. 10. Backscattered electron image of select model FeCrAl alloys after one year of LWR immersion testing. 


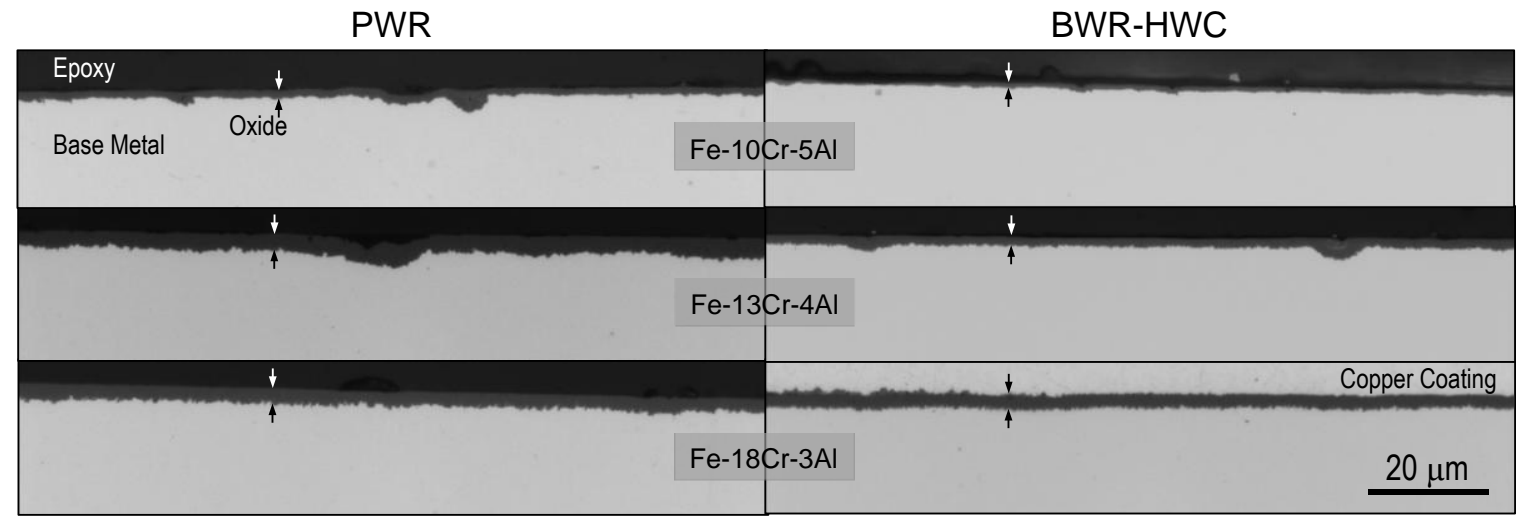

Fig. 11. Optical micrographs of the oxide layer cross section on the surface of select model FeCrAl alloys after one year of immersion testing in hydrogen water chemistry environments.

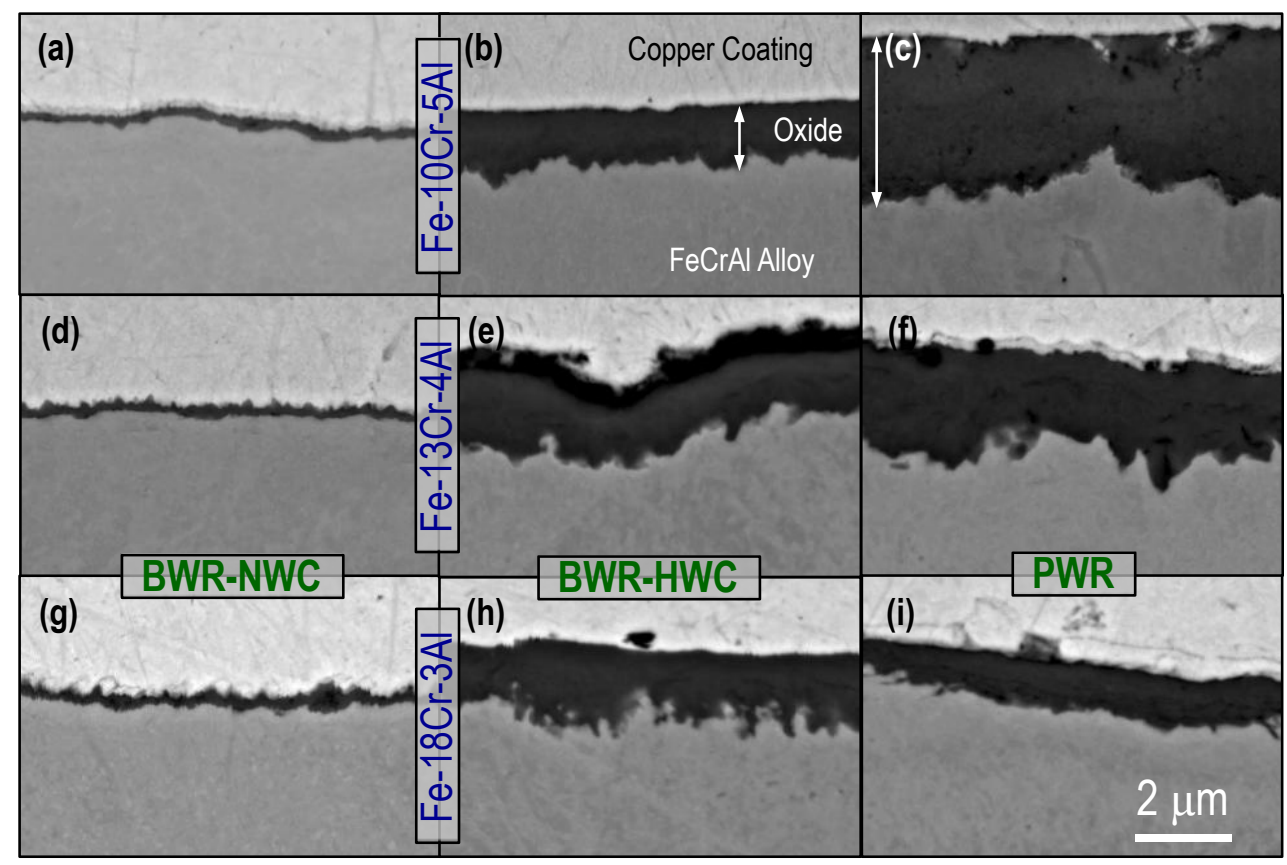

Fig. 12. Backscattered electron image of the cross section of the oxide layer on the surface of select model FeCrAl alloys after one year of LWR immersion testing. 


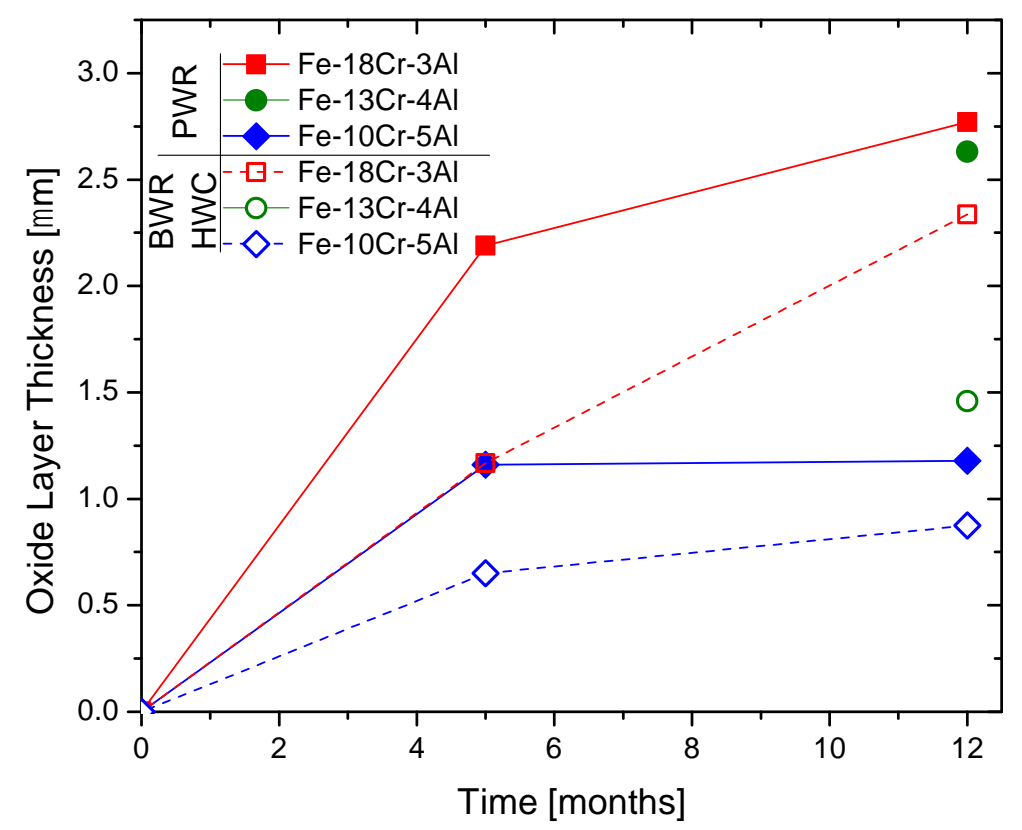

Fig. 13. Oxide layer thickness as a function of time formed on the surface of select model FeCrAl alloys tested in hydrogen water chemistry environments.

\subsubsection{TEM observations}

In order to observe the microstructure and chemistry of these thin oxide films, cross-sectional TEM was carried out on one alloy composition, Fe-10Cr-5Al, the lowest Cr-containing alloy. Figure 14 shows the analysis of the scale cross-section after one year in the BWR-NWC condition. The oxide layer is indeed very thin at $\sim 0.3 \mu \mathrm{m}$, consistent with the prediction based on mass change data in section 4.1. Although not shown here, the selected area electron diffraction (SAED) pattern generated from one of the large oxide crystals confirmed the hematite structure. The adjacent substrate appears to have recrystallized to a depth of $\sim 1.5 \mu \mathrm{m}$, a likely artifact of alloy surface preparation (polish with 600 grit paper), as reported previously [43]. Figure 14 also shows x-ray maps for Fe, Cr, Al, and O. Also in Fig. 15a the raw characteristic $x$-ray counts along the specified line scan outlined in Figure 14 are presented. Conversion of these counts to exact composition requires strict calibration that was not carried out here. Note that the oxide layer appears to contain $\mathrm{Fe}$ and $\mathrm{Cr}$ but no $\mathrm{Al}$ except near the oxide metal interface where the $\mathrm{Cr}$ and $\mathrm{Al}$ contents are higher and the Fe content drops, presumably because of the lower oxygen activity near the metal-oxide interface. Also note that in this qualitative representation the Fe concentration in the alloy decreases near the oxide metal interface, indicative of either an outward Fe flux towards the oxide or inward $\mathrm{Cr} / \mathrm{Al}$ flux away from the oxide. 


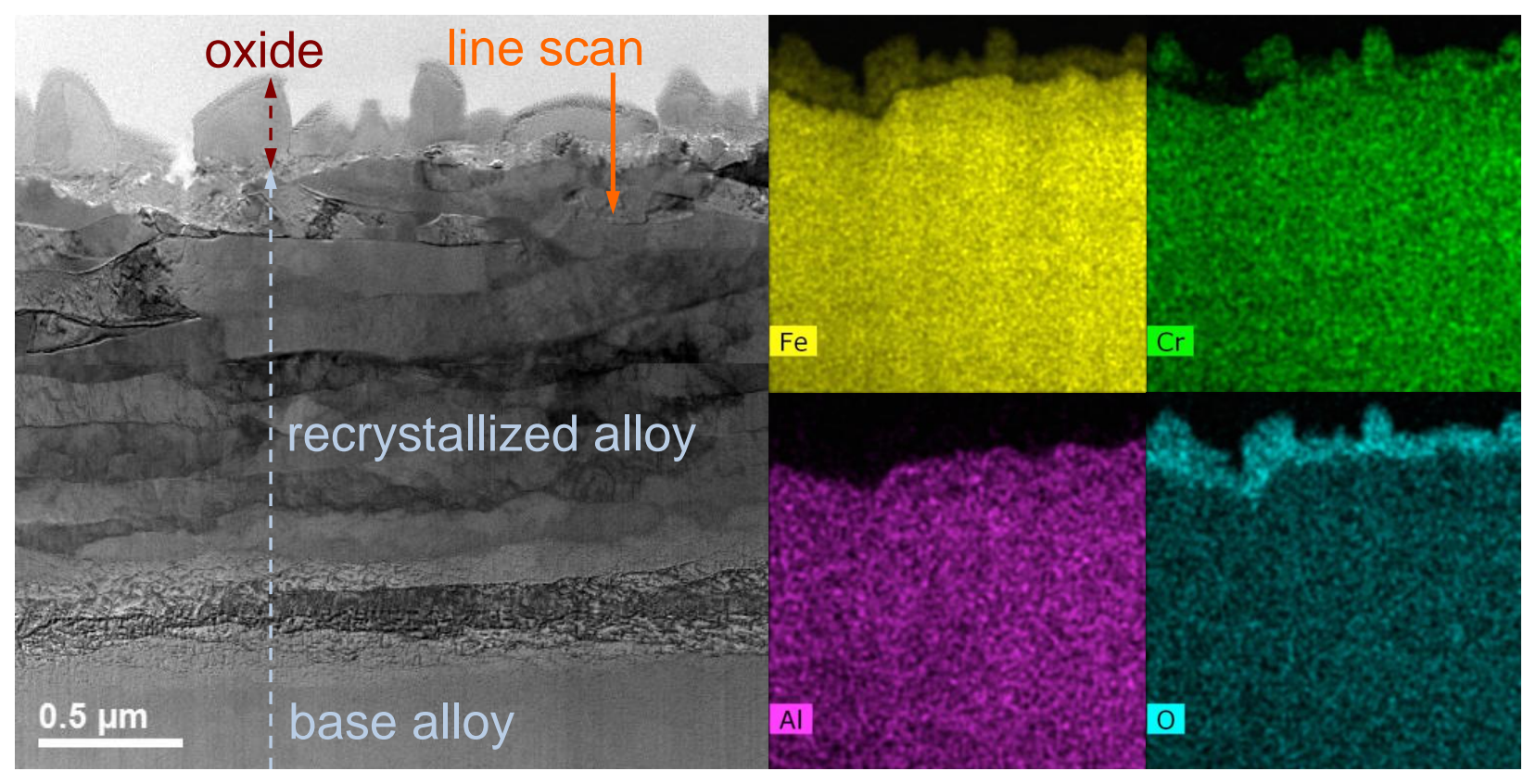

Fig. 14. Bright field STEM cross sectional image of the scale formed on Fe-10Cr-5Al after one year of BWR-NWC immersion testing along with $\mathrm{x}$-ray EDS maps of the major alloy constituents and $\mathrm{O}$.

Figure 16 shows the oxide scale formed on Fe-10Cr-5Al alloy after one year of BWR-HWC immersion testing. The scale is much thicker than the oxide formed in BWR-NWC and appears to have a layered or banded structure, suggesting that a $\mathrm{Cr}$ - and Al-enriched layer formed followed by a transition to Fe-rich oxide. The x-ray EDS map of the outer portion of the oxide shows that $\mathrm{Cr}$ and $\mathrm{Al}$ are present in the oxide where the former may be enriched at the grain boundaries. Fe-rich oxide particles free of $\mathrm{Cr}$ and $\mathrm{Al}$ are also present on the outermost surface, consistent with prior literature observations summarized in section 2.1. The $\mathrm{x}$-ray EDS line scan in Figure $15 \mathrm{~b}$ shows a relatively uniform distribution of $\mathrm{Fe}, \mathrm{Cr}$ and $\mathrm{Al}$ across most of the oxide thickness. However, Fe is depleted and enriched in the oxide and metal adjacent to their interface, respectively. The increase in Fe counts in the alloy near the oxide metal interface, opposite of what was observed in case of BWR-NWC exposures, may be indicative of either an outward $\mathrm{Cr} / \mathrm{Al}$ flux towards the oxide or inward Fe flux away from the oxide. Finally, deposition of Ni (from loop structural components) on the outer surface of the oxide is also observed.

Figure 17 shows the oxide scale formed on Fe-10Cr-5Al alloy after one year of PWR immersion testing. The scale features are very similar to the one formed on the surface of this alloys after BWR-HWC exposures. In both cases, if a recrystallized region existed at the alloy surface due to polishing, it was consumed by the growth of the thicker oxide. Electron diffraction analysis of the oxide layers formed on the surface of these specimens confirmed the magnetite-type structure of the scale. 

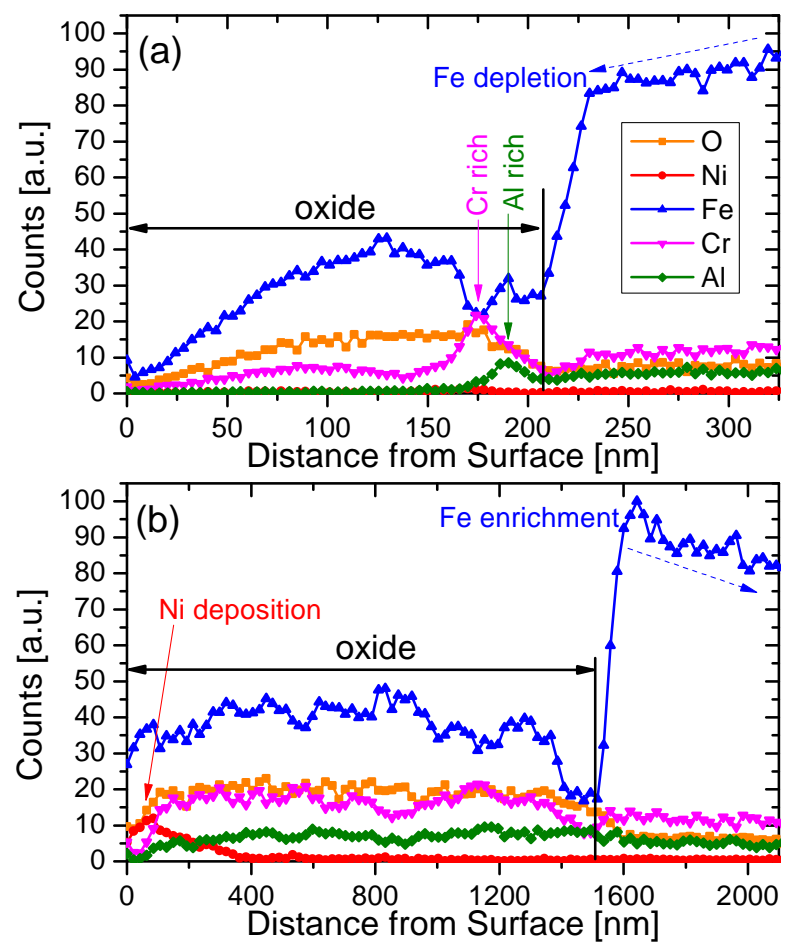

Fig. 15. X-ray EDS line scan profiles across the oxide film on the surface of Fe-10Cr-5Al alloy after one year of a) BWR-NWC, and b) BWR-HWC exposures.

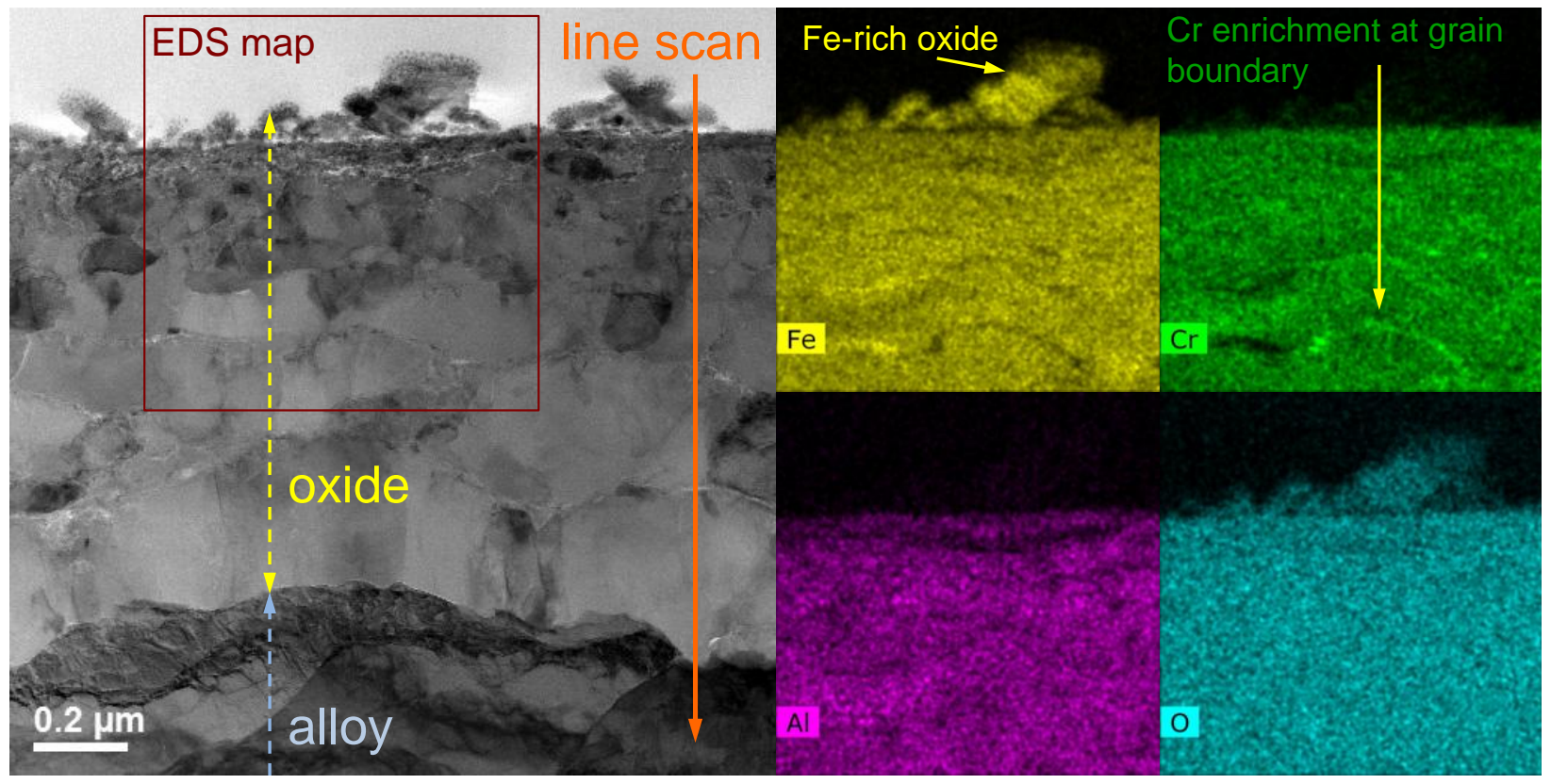

Fig. 16. Bright field STEM cross sectional image of the scale formed on Fe-10Cr-5Al after one year of BWR-HWC immersion testing along with x-ray EDS maps of the major alloy constituents and O. 


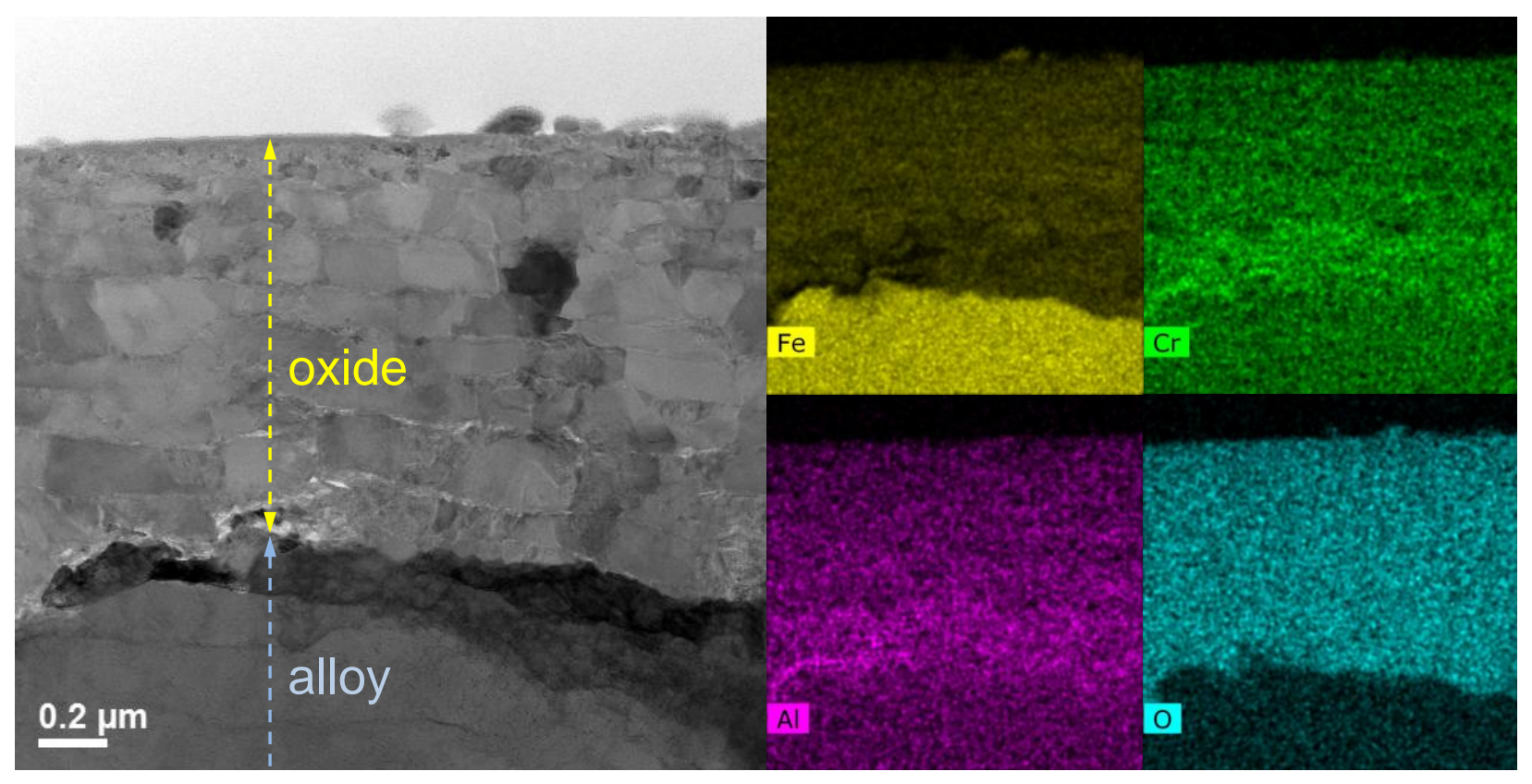

Fig. 17. Bright field STEM cross sectional image of the scale formed on Fe-10Cr-5Al after one year of PWR immersion testing along with $\mathrm{x}$-ray EDS maps of the major alloy constituents and $\mathrm{O}$.

\section{Discussion}

\subsection{Corrosion Kinetics}

As discussed in section 2, the corrosion process in the hydrogen water chemistry environments proceeds by oxidant species diffusion across the Cr-rich spinel layer (designated by $J_{\mathrm{O}}$ in Fig. 18) and the concurrent transport of Fe across that layer (designated by $J_{\mathrm{Fe}}$ in Fig. 18) to either form Fe-rich spineltype oxide at the outer interface or dissolve in water (designated by $J_{\text {diss }}$ in Fig. 18). $J_{\mathrm{O}}$ appears largely independent of the other processes, therefore, parabolic growth kinetics govern mass gain as a result of growth of the Cr-rich spinel layer $\left(\Delta w_{1}\right)$ :

$$
\Delta w_{1}=k_{1} \sqrt{t}
$$

where $k_{1}$ is the parabolic oxidation rate constant and $t$ is time. Accordingly, the thickness of this Cr-rich spinel layer, $x$, is given by:

$$
x=\frac{k_{1} \sqrt{t}}{\rho_{\text {ox }}}
$$

where $\rho_{\mathrm{ox}}$ is assumed to be the density of oxygen in chromite, $1.44 \mathrm{~g} / \mathrm{cm}^{3}$. The flux of Fe across the Crrich spinel layer may now be defined as:

$$
J_{F e}=-D_{F e} \frac{\left(C_{S}-C_{B}\right)}{x}
$$

where $D_{\mathrm{Fe}}$ is the diffusivity of $\mathrm{Fe}$ in the Cr-rich spinel and $C_{\mathrm{B}}$ and $C_{\mathrm{S}}$ are the Fe concentrations at the oxide-metal and aqueous-oxide interfaces, respectively. The dissolution flux is given by: 


$$
J_{\text {diss }}=k_{d}\left(C_{S}-C_{\infty}\right)
$$

where $k_{\mathrm{d}}$ and $C_{\infty}$ are the dissolution rate constant and Fe concentration in the bulk fluid, respectively. Note that if $C_{\infty}$ is smaller and larger than the solubility limit of magnetite in water [44-47] at the given corrosion temperature, magnetite dissolves and deposits on the surface, respectively. Assuming steady state conditions, one can equate the diffusive and dissolution flux terms per the standard Deal and Grove model [48]. After substituting for $x$ using Eq. (2), the following relationship describes the outward Fe mass flux:

$$
\frac{M}{N_{a v}} J_{F e}=\frac{M}{N_{a v}} k_{d} D_{F e} \rho_{o x}\left(C_{B}-C_{\infty}\right) \frac{1}{k_{1} k_{2} \sqrt{t}+\rho_{o x} D_{F e}}
$$

where $M$ is the molar mass of Fe. The mass of dissolved Fe, $\Delta w_{2}$, as a function of time may now be determined by integrating Eq. (5) with time to arrive at the following:

$\Delta w_{2}=\int \frac{M}{N_{a v}} J_{F e} d t=2 \frac{M}{N_{a v}} k_{d} D_{F e} \rho_{o x}\left(C_{B}-C_{\infty}\right)\left(\frac{k_{1} k_{d} \sqrt{t}-\rho_{o x} D_{F e} \log \left(\rho_{o x} D_{F e}+k_{1} k_{d} \sqrt{t}\right)}{\left(k_{1} k_{d}\right)^{2}}+\frac{\rho_{o x} D_{F e} \log \left(\rho_{o x} D_{F e}\right)}{\left(k_{1} k_{d}\right)^{2}}\right)$

where the constant of integration is determined by assuming $\Delta w_{2}$ at the onset of the process is nil. In the experimental setup of this study, Fe-ion free water was continually fed into the autoclave that was subsequently filtered. Therefore $C_{\infty}$ is assumed to be negligible, however, for the reactor application, the presence of appreciable amounts of Fe ions in solution will affect the size and density of Fe-rich spinel precipitates on the surface and the kinetics of Fe release or deposition on the fuel and other primary loop components. In a number of studies where appreciable amounts of dissolved magnetite were present in the water, large Fe-rich spinel crystals covered the specimen surface [19-21]. Also in this study, as the Crrich oxide grew, the diffusive flux $\left(J_{\mathrm{Fe}}\right)$ became the rate-limiting step for Fe dissolution. In other words $k_{\mathrm{d}}$ $x \gg D_{\mathrm{Fe}}$, thereby reducing the complex correlation in Eq. (6) to another simple parabolic equation:

$$
\Delta w_{2} \approx k_{2} \sqrt{t}
$$

where $k_{2}$ is the apparent parabolic rate constant. The total mass change in the specimen, $\Delta w_{\mathrm{T}}$, is therefore calculated as:

$$
\Delta w_{T}=\Delta w_{1}-\Delta w_{2}=\left(k_{1}-k_{2}\right) \sqrt{t}
$$

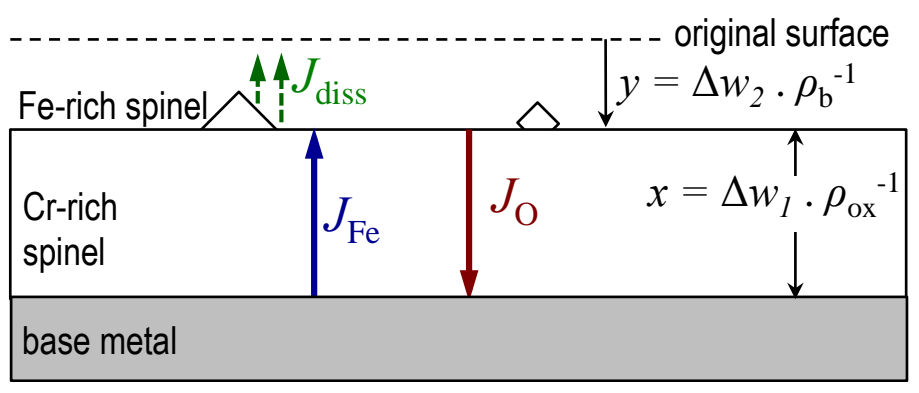

Fig. 18. Schematic of flux processes that govern aqueous corrosion of $\mathrm{FeCrAl}$ alloys in high-temperature water. 
Total mass change data as a function of time are shown in Fig. 4. $\Delta w_{1}$ as a function of time may also be determined from the thickness data in Fig. 13. Therefore, using Eq. (8), the rate constants for the oxide layer growth, $k_{1}$, and Fe dissolution, $k_{2}$, may be determined. These parameters are tabulated in Table 3 . Note that $k_{2}$ is not applicable for BWR-NWC exposures since no mass loss was observed, only parabolic oxide growth. For the hydrogen water chemistry tests, $k_{1}$ and $k_{2}$ are only reported for the alloys where the limited oxide layer thickness data was available, and when only one thickness point was available no standard error in the rate could be determined. The calculated oxidation rate constant, $k_{1}$, tends to increase with $\mathrm{Cr}$ content in the alloy for the hydrogen water chemistry tests while no trend was noted as a function of alloy composition for the values calculated for the BWR-NWC exposures. Average rate constants are reported in Table 3 since the values appeared to be close to one another. Comparing the rate constants determined for the hydrogen water chemistries, the rates were higher for the PWR exposures than those for BWR-HWC. This difference could be attributed to higher temperature for the PWR exposures.

Table 3. Parabolic oxidation $\left(k_{1}\right)$ and dissolution $\left(k_{2}\right)$ rate constants for various FeCrAl alloys.

\begin{tabular}{|l|c|c|c|c|c|}
\hline & \multicolumn{2}{|c|}{ PWR } & \multicolumn{2}{c|}{ BWR-HWC } & BWR-NWC \\
\hline $\mathrm{mg}-\mathrm{cm}^{-2} \mathrm{~h}^{-1 / 2}$ & $k_{1}$ & $k_{2}$ & $k_{1}$ & $k_{2}$ & $k_{1}$ \\
\hline $\mathrm{Fe}-10 \mathrm{Cr}-5 \mathrm{Al}$ & $(2.05 \pm 0.30) \times 10^{-3}$ & $(7.09 \pm 0.42) \times 10^{-3}$ & $(1.38 \pm 0.06) \times 10^{-3}$ & $(4.41 \pm 0.26) \times 10^{-3}$ & $(3.63 \pm 0.46) \times 10^{-4}$ \\
\hline $\mathrm{Fe}-12 \mathrm{Cr}-5 \mathrm{Al}$ & & & & & $(2.66 \pm 0.60) \times 10^{-4}$ \\
\hline Fe-13Cr-4Al & $3.96 \times 10^{-3}$ & $(7.49 \pm 1.93) \times 10^{-3}$ & $2.20 \times 10^{-3}$ & $(6.70 \pm 0.31) \times 10^{-3}$ & $(4.51 \pm 0.50) \times 10^{-4}$ \\
\hline Fe-13Cr-4Al SG & & & & & $(1.60 \pm 0.35) \times 10^{-4}$ \\
\hline Fe-15Cr-4Al & & & & & $(5.34 \pm 0.92) \times 10^{-4}$ \\
\hline Fe-18Cr-3Al & $(4.45 \pm 3.02) \times 10^{-3}$ & $(7.83 \pm 0.28) \times 10^{-3}$ & $(3.28 \pm 0.26) \times 10^{-3}$ & $(6.04 \pm 0.16) \times 10^{-3}$ & $(2.97 \pm 0.55) \times 10^{-4}$ \\
\hline Average & $3.49 \times 10^{-3}$ & $7.47 \times 10^{-3}$ & $2.29 \times 10^{-3}$ & $5.72 \times 10^{-3}$ & $3.45 \times 10^{-4}$ \\
\hline
\end{tabular}

\subsection{Comparison to Zircaloy corrosion}

It is useful to provide a comparison between the mass gains observed for the model FeCrAl alloys examined in this study and a typical Zr-based alloy currently used in LWRs. Figure 19 shows a comparison between the mass gain and thickness of the base metal consumed as a function of time. In the figure, PWR corrosion data for Zircaloy 4 at $320^{\circ} \mathrm{C}$ from loop tests in ref. [49] as well as Figure 3 of this study are included. Also, $360^{\circ} \mathrm{C}$ autoclave corrosion data for Zircaloy 4 in pure water per ASTM G2 [34] were shown. Curves for the $\mathrm{FeCrAl}$ alloys are calculated based on the average kinetic parameters determined in Table 3. The extent of thickness loss for FeCrAl alloys after one year of corrosion inside a flowing autoclave loop is $\sim 2 \mu \mathrm{m}$ or less, comparable to Zirclaoy- 4 at similar temperatures, and essentially negligible. The results of this study extend for only one year, and longer periods should be assessed. However, austenitic alloys such type 304 SS (same family as type 310 SS) have been used in reactor components for over 40 years and the general corrosion phenomena has never been a matter of concern due to the low corrosion or dissolution rates experienced by these alloys in $\sim 300^{\circ} \mathrm{C}$ water environments. This study shows that ferritic FeCrAl alloys behave similarly to the well-known behavior of austenitic $\mathrm{FeCrNi}$ alloys. Moreover, for a cladding application, the time in the reactor environment will be shorter than 10 years, therefore, no general corrosion issues are anticipated in either oxidizing or reducing high temperature water reactor environments. 
This study was conducted in the absence of irradiation. Mechanisms such as radiation induced segregation, $\alpha^{\prime}$ formation, as well as other microstructural effects on the alloy or scale could affect the kinetics under irradiation. This is certainly the case for Zr-based alloys where significant acceleration in the corrosion rate (roughly an order of magnitude) under irradiation has been observed when compared to that in autoclave experiments $[50,51]$.
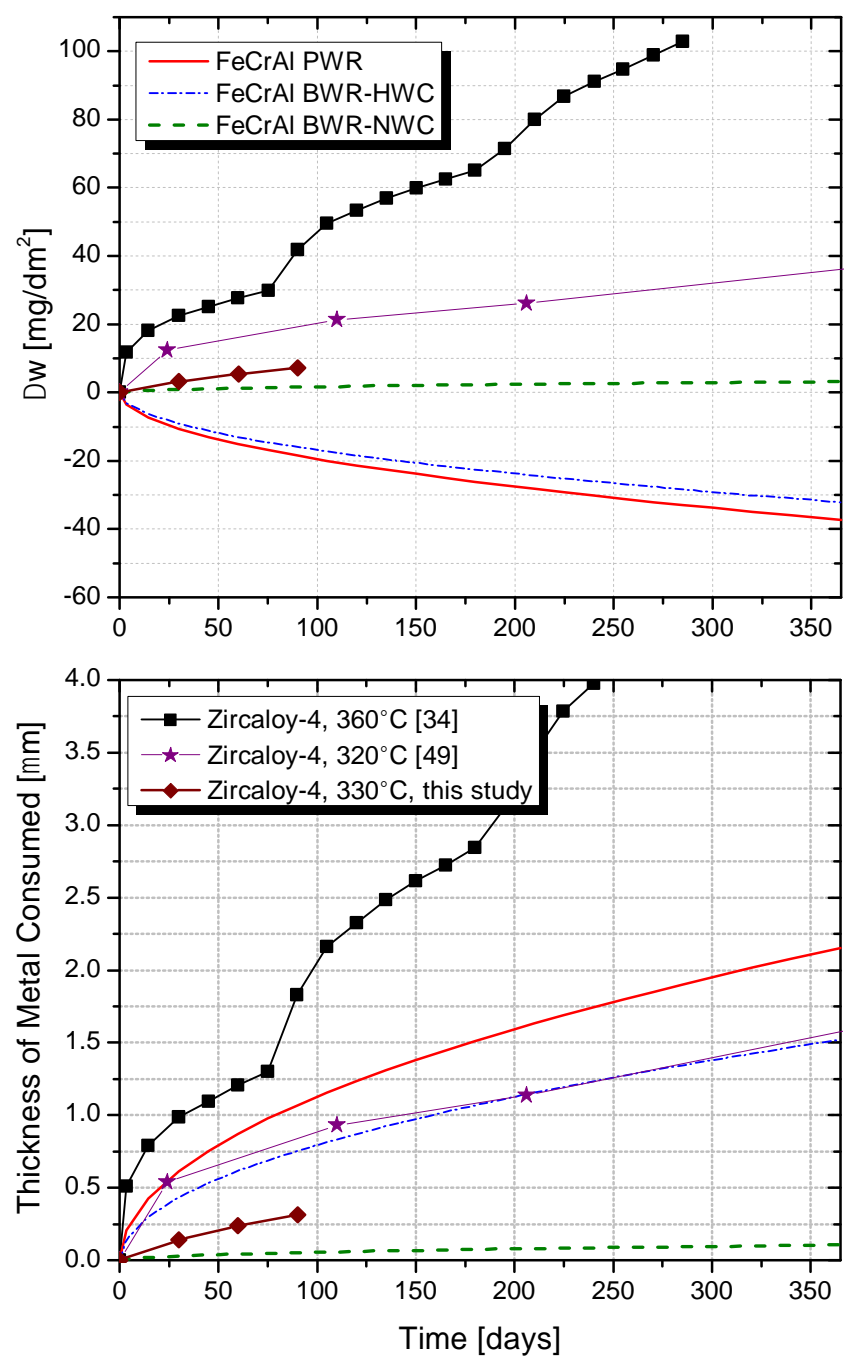

Fig. 19. Comparison between the results of mass gain and thickness of metal consumed from autoclave corrosion tests on Zircaloy-4 [34, 49] and model FeCrAl alloys.

\section{Conclusions}

The following conclusions can be drawn from the results and analysis in this paper:

- All austenitic and ferritic alloys in this study experienced mass loss after immersion tests in hydrogen water chemistry autoclave environments $\left(0.3-4 \mathrm{ppm}\right.$ dissolved $\left.\mathrm{H}_{2}\right)$ while mass gain occurred in case of normal water chemistry test ( $1 \mathrm{ppm}$ dissolved $\mathrm{O}_{2}$ ). 
- For the model FeCrAl alloys with $10-15 \mathrm{wt} \% \mathrm{Cr}$ and 3-5wt\% $\mathrm{Al}$ hydrogen water chemistry tests resulted in formation of a Cr-rich spinel oxide (chromite) that was furnished with Fe-rich spinel crystals on its outer surface. Dissolution of the Fe-rich crystals at the surface resulted in net mass loss in these samples. The growth of the inner chromite appeared to follow parabolic kinetics, likely limited by inward diffusion of the oxidizing species. The mass loss rate due to dissolution of Fe-rich precipitates also followed parabolic kinetics since it was limited by arrival of Fe across the chromite layer to the surface rather than the dissolution rate itself that proved fast in the flowing loop environment.

- The same model alloys formed a protective hematite scale on the surface after normal water chemistry tests following parabolic kinetics.

- The maximum thickness loss after one year of LWR water corrosion in the absence of irradiation was $\sim 2 \mu \mathrm{m}$ in these alloys. This small loss is inconsequential for the fuel cladding application with thickness range in hundreds of micrometers.

\section{Acknowledgments}

The work presented in this paper was supported by the Advanced Fuels Campaign of the Fuel Cycle R\&D program in the Office of Nuclear Energy, US Department of Energy. The microscopy was supported through a user proposal by ORNL's Center for Nanophase Materials Sciences (CNMS), which is a U.S. Department of Energy, Office of Science User Facility. The authors would like to thank S.J Pawel and A. Willoughby for assistance in preparing the specimens. K.G. Field and J. McMurray provided useful comments on the manuscript.

\section{References}

[1] K. A. Terrani, S. J. Zinkle, and L. L. Snead, "Advanced oxidation-resistant iron-based alloys for LWR fuel cladding," Journal of Nuclear Materials, vol. 448, pp. 420-435, 2014.

[2] B. A. Pint, K. A. Terrani, M. P. Brady, T. Cheng, and J. R. Keiser, "High Temperature Oxidation of Fuel Cladding Candidate Materials in Steam-Hydrogen Environments," Journal of Nuclear Materials, vol. 440, pp. 420-427, 2013.

[3] B. A. Pint, K. A. Terrani, Y. Yamamoto, and L. L. Snead, "Material Selection for Accident Tolerant Fuel Cladding," Metallurgical and Materials Transactions E, vol. 2, pp. 190-196, 2015.

[4] B. A. Pint, K. A. Unocic, and K. A. Terrani, "The Effect of Steam on the High Temperature Oxidation Behavior of Alumina-Forming Alloys," Mater. High Temp. , vol. 32 pp. 28-35, 14-16 April 2015.

[5] G. C. Rybicki and J. L. Smialek, "Effect of the $\theta-\alpha-A 12 \mathrm{O} 3$ transformation on the oxidation behavior of $\beta$ NiAl+ Zr," Oxidation of Metals, vol. 31, pp. 275-304, 1989.

[6] D. Young, D. Naumenko, L. Niewolak, E. Wessel, L. Singheiser, and W. Quadakkers, "Oxidation kinetics of Y-doped FeCrAl-alloys in low and high pO2 gases," Materials and Corrosion, vol. 61, pp. 838-844, 2010.

[7] E. J. Opila and D. L. Myers, "Alumina volatility in water vapor at elevated temperatures," Journal of the American Ceramic Society, vol. 87, pp. 1701-1705, 2004.

[8] F. Ford, B. Gordon, and R. Horn, "Corrosion in boiling water reactors," in ASM Handbook. vol. 13, ed, 2006, p. 341.

[9] P. Scott and P. Combrade, "Corrosion in Pressurized Water Reactors," in ASM Handbook. vol. 13, ed, 2006, p. 362.

[10] P. Andresen, K. Arioka, S. Bruemmer, J. Busby, R. Dyle, P. Ford, et al., "Expanded Materials Degradation Assessment (EMDA), Volume 2: Aging of Core Internals and Piping Systems, NUREG/CR-7153, Vol. 2, ORNL/TM-2013/532," US Nuclear Regulatory Commission2013. 
[11] M. Mathon, Y. De Carlan, G. Geoffroy, X. Averty, A. Alamo, and C. De Novion, "A SANS investigation of the irradiation-enhanced $\alpha-\alpha$ ' phases separation in 7-12 Cr martensitic steels," Journal of nuclear materials, vol. 312, pp. 236-248, 2003.

[12] K. G. Field, X. Hu, K. C. Littrell, Y. Yamamoto, and L. L. Snead, "Radiation tolerance of neutronirradiated model Fe-Cr-Al alloys," Journal of Nuclear Materials, vol. 465, pp. 746-755, 2015.

[13] P. D. Edmondson, S. A. Briggs, Y. Yamamoto, R. H. Howard, K. Sridharan, K. A. Terrani, et al., "Irradiation-enhanced $\alpha$ precipitation in model FeCrAl alloys," Scripta Materialia, vol. 116, pp. 112-116, 2016.

[14] J. Robertson, "The mechanism of high temperature aqueous corrosion of stainless steels," Corrosion Science, vol. 32, pp. 443-465, 1991.

[15] B. Stellwag, "The mechanism of oxide film formation on austenitic stainless steels in high temperature water," Corrosion science, vol. 40, pp. 337-370, 1998.

[16] A. Atkinson, "Transport processes during the growth of oxide films at elevated temperature," Reviews of Modern Physics, vol. 57, p. 437, 1985.

[17] J. Robertson, "The mechanism of high temperature aqueous corrosion of steel," Corrosion Science, vol. 29, pp. 1275-1291, 1989.

[18] R. Tapping, R. Davidson, E. McAlpine, and D. Lister, "The composition and morphology of oxide films formed on type 304 stainless steel in lithiated high temperature water," Corrosion Science, vol. 26, pp. 563$576,1986$.

[19] D. Lister, R. Davidson, and E. McAlpine, "The mechanism and kinetics of corrosion product release from stainless steel in lithiated high temperature water," Corrosion science, vol. 27, pp. 113-140, 1987.

[20] T. Terachi, T. Yamada, T. Miyamoto, K. Arioka, and K. Fukuya, "Corrosion behavior of stainless steels in simulated PWR primary water-Effect of chromium content in alloys and dissolved hydrogen—," Journal of nuclear science and technology, vol. 45, pp. 975-984, 2008.

[21] S. Ziemniak and M. Hanson, "Corrosion behavior of 304 stainless steel in high temperature, hydrogenated water," Corrosion Science, vol. 44, pp. 2209-2230, 2002.

[22] M. Da Cunha Belo, M. Walls, N. Hakiki, J. Corset, E. Picquenard, G. Sagon, et al., "Composition, structure and properties of the oxide films formed on the stainless steel 316L in a primary type PWR environment," Corrosion science, vol. 40, pp. 447-463, 1998.

[23] I. G. Wright and R. Dooley, "A review of the oxidation behaviour of structural alloys in steam," International Materials Reviews, vol. 55, pp. 129-167, 2010.

[24] R. Dieckmann, "Point defects and transport in non-stoichiometric oxides: solved and unsolved problems," Journal of Physics and Chemistry of Solids, vol. 59, pp. 507-525, 1998.

[25] J. A. Van Orman and K. L. Crispin, "Diffusion in oxides," Reviews in Mineralogy and Geochemistry, vol. 72, pp. 757-825, 2010.

[26] D. J. Park, H. G. Kim, J. Y. Park, Y. I. Jung, J. H. Park, and Y. H. Koo, "A study of the oxidation of FeCrAl alloy in pressurized water and high-temperature steam environment," Corrosion Science, vol. 94, pp. 459-465, 2015.

[27] B. Sundman, B. Jansson, and J.-O. Andersson, "The thermo-calc databank system," Calphad, vol. 9, pp. 153-190, 1985.

[28] R. Cerbo and A. Seybolt, "Lattice Parameters of the $\alpha-\mathrm{Fe} 2 \mathrm{O} 3-\mathrm{Cr} 2 \mathrm{O} 3$ Solid Solution," Journal of the American Ceramic Society, vol. 42, pp. 430-431, 1959.

[29] S. Musić, S. Popović, and M. Ristić, "Chemical and structural properties of the system Fe2O3-Cr2O3," Journal of materials science, vol. 28, pp. 632-638, 1993.

[30] Y. Yamamoto, B. A. Pint, K. A. Terrani, K. G. Field, Y. Yang, and L. L. Snead, "Development and Property Evaluation of Nuclear Grade Wrought FeCrAl Fuel Cladding for Light Water Reactors," Journal of Nuclear Materials, vol. 467, pp. 703-716, 2015.

[31] K. A. Terrani, Y. Yang, Y.-J. Kim, R. Rebak, H. Meyer, and T. J. Gerczak, "Hydrothermal corrosion of $\mathrm{SiC}$ in LWR coolant environments in the absence of irradiation," Journal of Nuclear Materials, vol. 465, pp. 488-498, 2015.

[32] A. C. Larson and R. B. Von Dreele, "Gsas," General Structure Analysis System. LANSCE, MS-H805, Los Alamos, New Mexico, 1994.

[33] A. T. Motta, A. Couet, and R. J. Comstock, "Corrosion of Zirconium Alloys Used for Nuclear Fuel Cladding," Annual Review of Materials Research, vol. 45, pp. 311-343, 2015. 
[34] B. de Gabory, A. T. Motta, and K. Wang, "Transmission electron microscopy characterization of Zircaloy4 and ZIRLO ${ }^{\text {TM }}$ oxide layers," Journal of Nuclear Materials, vol. 456, pp. 272-280, 2015.

[35] A. Muan, "Phase relations in chromium oxide-containing systems at elevated temperatures," Geochimica et Cosmochimica Acta, vol. 39, pp. 781-802, 1975.

[36] T. Grygar, P. Bezdicka, J. Dedecek, E. Petrovsky, and O. Schneeweiss, "Fe 2O 3-Cr 2O 3 system revised," CERAMICS SILIKATY, vol. 47, pp. 32-39, 2003.

[37] H. STEINWEHR, "Gitterkonstanten im System $\alpha$-(Al, Fe, Cr) $2 \mathrm{O} 3$ und ihr Abweichen von der Vegardregel," Zeitschrift für Kristallographie-Crystalline Materials, vol. 125, pp. 377-403, 1967.

[38] H. Yearian, J. Kortright, and R. Langenheim, "Lattice Parameters of the FeFe (2-x) CrxO4 Spinel System," The Journal of Chemical Physics, vol. 22, pp. 1196-1198, 1954.

[39] M. Francombe, "Lattice changes in spinel-type iron chromites," Journal of Physics and Chemistry of Solids, vol. 3, pp. 37-43, 1957.

[40] H. Levinstein, M. Robbins, and C. Capio, "A crystallographic study of the system FeCr $2 \mathrm{O} 4 \cdot \mathrm{Fe} 3 \mathrm{O} 4$ (Fe 2+ Fe 3+ x Cr 2- x O 4)," Materials Research Bulletin, vol. 7, pp. 27-34, 1972.

[41] A. Turnock and H. Eugster, "Fe-Al Oxides: Phase Relationships below 1,000 C," Journal of Petrology, vol. 3, pp. 533-565, 1962.

[42] D. Lenaz and H. Skogby, "Structural changes in the FeAl2O4-FeCr2O4 solid solution series and their consequences on natural Cr-bearing spinels," Physics and chemistry of minerals, vol. 40, pp. 587-595, 2013.

[43] J. Kaneda, M. Koshiishi, M. M. Morra, and R. B. Rebak, "Microstructural characterization of surface modified Alloy 82 welds regarding susceptibility to environmentally assisted cracking," in CORROSION 2011, 2011.

[44] F. Sweeton and C. Baes, "The solubility of magnetite and hydrolysis of ferrous ion in aqueous solutions at elevated temperatures," The Journal of Chemical Thermodynamics, vol. 2, pp. 479-500, 1970.

[45] K. Dinov, K. Ishigure, C. Matsuura, and D. Hiroishi, "Solubility of magnetite in high temperature water and an approach to generalized solubility computations," Journal of nuclear materials, vol. 207, pp. 266273, 1993.

[46] P. R. Tremaine and J. C. LeBlanc, "The Solubility of Magnetite and the Hydrolysis and Oxidation of Fe2+ in Water to 300 C," Journal of solution chemistry, vol. 9, pp. 415-442, 1980.

[47] P. R. Tremaine, R. Von Masscow, and G. Shierman, "A calculation of Gibbs free energies for ferrous ions and the solubility of magnetite in $\mathrm{H} 2 \mathrm{O}$ and D $2 \mathrm{O}$ to 300 C," Thermochimica Acta, vol. 19, pp. 287-300, 1977.

[48] B. E. Deal and A. Grove, "General relationship for the thermal oxidation of silicon," Journal of Applied Physics, vol. 36, pp. 3770-3778, 1965.

[49] P. Billot, P. Beslu, A. Giordano, and J. Thomazet, "Development of a mechanistic model to assess the external corrosion of the Zircaloy claddings in PWRs," in Zirconium in the Nuclear Industry: Eighth International Symposium, 1989.

[50] B. Cox, "Some thoughts on the mechanisms of in-reactor corrosion of zirconium alloys," Journal of Nuclear Materials, vol. 336, pp. 331-368, 2005.

[51] T. Karlsen and C. Vitanza, "Effects of pressurized water reactor (PWR) coolant chemistry on Zircaloy corrosion behavior," in Zirconium in the Nuclear Industry: Tenth International Symposium, 1994. 